\section{A Ariviog

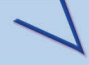

Archive for

Organic Chemistry
The Free Internet Journal

for Organic Chemistry
Paper

Arkivoc 2017, part ii, 235-250

\title{
Synthesis of new dithiolethione and methanethiosulfonate systems endowed with pharmaceutical interest
}

Elena Gabriele, ${ }^{\mathrm{a}}$ Federica Porta, ${ }^{\text {a }}$ Giorgio Facchetti, ${ }^{a}$ Corinna Galli, ${ }^{a}$ Arianna Gelain, ${ }^{a}$ Fiorella Meneghetti, ${ }^{a}$ Isabella Rimoldi, ${ }^{a}$ Sergio Romeo, ${ }^{a}$ Stefania Villa, ${ }^{a}$ Chiara Ricci, ${ }^{b}$ Nicola Ferri, ${ }^{c}$ Akira Asai, ${ }^{d}$ Daniela Barlocco, ${ }^{a}$ and Anna Sparatore*a

${ }^{a}$ Dept. Pharmaceutical Sciences, Università degli Studi di Milano, Via L. Mangiagalli 25, 20133 Milano, Italy

${ }^{b}$ Dept. Pharmacological and Biomolecular Sciences, Università di Milano, Via Balzaretti 9, 20133 Milano, Italy

${ }^{c}$ Dept. Pharmaceutical and Pharmacological Sciences, Università di Padova, Via Marzolo 5, 35131 Padova, Italy

${ }^{d}$ Center for Drug Discovery, Graduate School of Pharmaceutical Sciences, University of Shizuoka 52-1 Yada, Suruga-ku, Shizuoka 422-8526, Japan

$\S$ These authors equally contributed to this work

Email: anna.sparatore@unimi.it

Dedicated to Prof. Jacek Młochowski on the occasion of his $80^{\text {th }}$ anniversary

Received 07-19-2016

Accepted 09-09-2016

Published on line 09-20-2016

\section{Abstract}

Here we report synthetic methodology affording in the most efficient way the rapid preparation of new dithiolethiones (DTTs) and methanethiosulfonates (MTSs). These were evaluated as STAT3 inhibitors since these electrophilic systems could react with thiol groups of STAT3-SH2 domain. The results showed that MTSs strongly interacted with the $\mathrm{SH} 2$ domain, whereas the corresponding DTTs possessed lower affinity, independently from the nature of the linked heterocyclic scaffold.

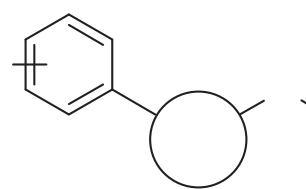

1,2,5-oxadiazole -methylimidazole

$\mathrm{NHCO}$
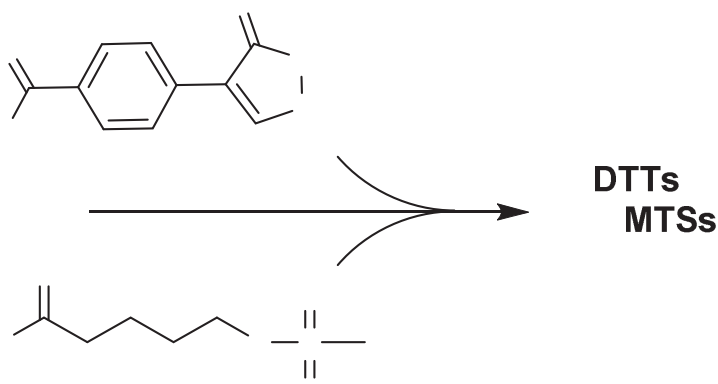

Keywords: 1,2,5-Oxadiazole, $\mathrm{N}$-Methylimidazole, STAT3-SH2 domain, Coupling reactions 


\section{Introduction}

Recent literature ${ }^{1,2}$ shows considerable interest in the chemistry and bioactivity of 1,2-dithiole-3-thiones (DTTs) and methanethiosulfonates (MTSs). Both moieties have been reported to exert chemopreventative and anticancer activities. ${ }^{3-7}$ Since these electrophilic systems are able to react with thiol groups, and therefore, hypothetically, with cysteines in biologically important peptides and proteins, ${ }^{8,9}$ we considered that the introduction of these moieties on a suitable scaffold could lead to new inhibitors able to covalently link the active site of several transcription factors. A similar behavior was observed between a DTT derivative and NFkB (Nuclear Factor Kappa-light-chain-enhancer of activated B cells). ${ }^{10}$ As STAT3 (Signal Transducer and Activator of Transcription 3) occupies a noteworthy position in cancer biology, ${ }^{11}$ we decided to explore the relevance of these chemical systems against this target. Among the recognized STAT3 direct inhibitors reported in the literature many are sulfur-containing compounds, such as sulfones (Stattic), ${ }^{12}$ sulfonates (S31201) $)^{13}$ or sulfonamides (SF-1-066 and BP-1-102), ${ }^{13}$ but no DTTs or MTSs have been so far considered. As we recently published our results on several oxadiazole derivatives able to interfere with the STAT3 signaling pathway, ${ }^{14-17}$ we thought it of interest to link this heterocyclic scaffold to DTT and MTS moieties. In this way, we aimed to promote the targeting of the new compounds towards the SH2 (Src Homology 2) domain.
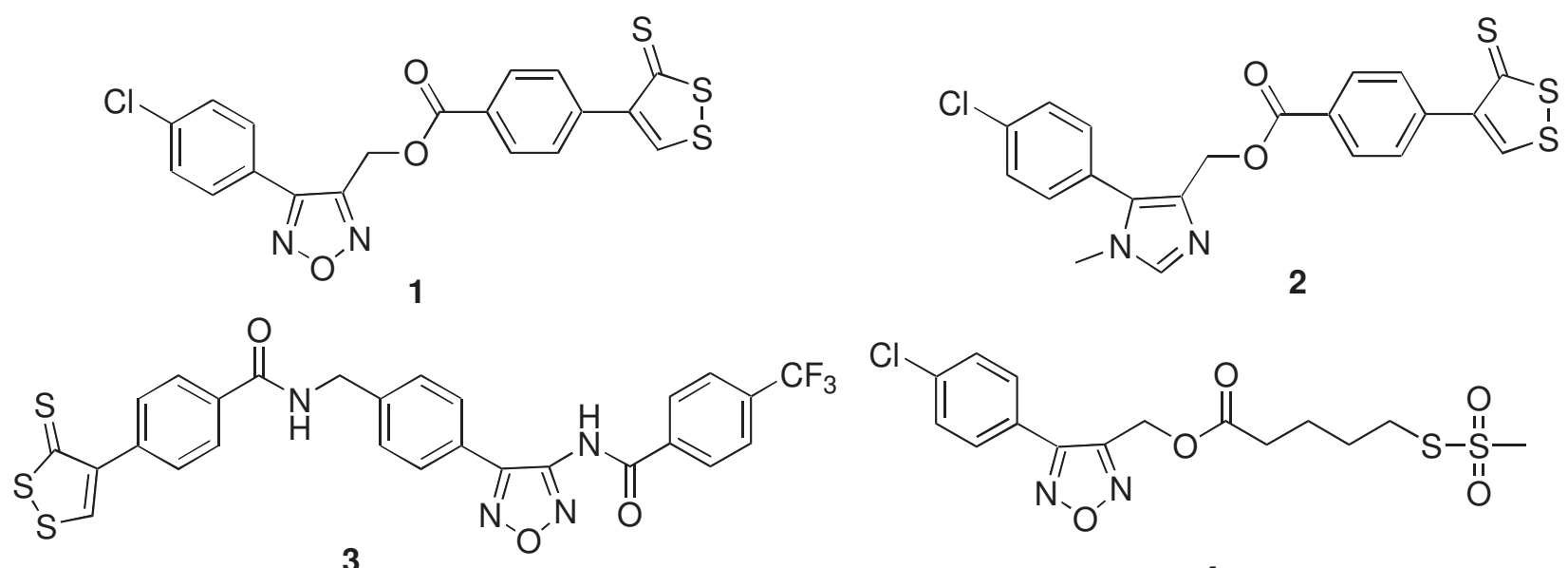<smiles>CS(=O)(=O)SCCCCC(=O)OCc1nonc1-c1ccc(Cl)cc1</smiles><smiles>Cn1cnc(COC(=O)CCCCSS(C)(=O)=O)c1-c1ccc(Cl)cc1</smiles>

5<smiles>CS(=O)(=O)SCCCCC(=O)NCc1ccc(-c2nonc2NC(=O)c2ccc(C(F)(F)F)cc2)cc1</smiles><smiles>CS(=O)(=O)SCCCCC(=O)Oc1ccc(-c2nonc2NC(=O)c2ccc(C(F)(F)F)cc2)cc1</smiles>

7<smiles>CS(=O)(=O)SCCCCC(=O)Nc1ccc(C(=O)Nc2nonc2-c2ccc(Cl)cc2)cc1</smiles>

8

Figure 1. Structures of the new synthesized compounds. 
In this paper, we describe synthetic methodology affording in the most efficient way the rapid preparation of new inhibitors having DTT or MTS systems linked to differently substituted 1,2,5-oxadiazole rings through an ester (1, $\mathbf{4}$ and $\mathbf{7})$ or an amidic bond (3, $\mathbf{6}$ and $\mathbf{8})$ (Figure 1). In addition, we synthesized the bioisosteric analogues of $\mathbf{1}$ and $\mathbf{4}$, by replacing the oxadiazole with a substituted $N$-methylimidazole ( 2 and $\mathbf{5}$ ).

\section{Results and Discussion}

\section{Chemistry}

The key intermediates for the synthesis of the final products (1-8) were prepared according to the following methods. The synthesis of compounds 9, 4-(3-thioxo-3H-1,2-dithiol-4-yl)benzoic acid, and 10, 5(methylsulfonylthio)pentanoic acid, was achieved following literature procedures. ${ }^{18,19}$ Intermediates 12, 15, 23, 25 and 27 were prepared as shown in Schemes 1 and 2.

The synthesis of 12, bearing a suitable 3-hydroxymethyl substituent, was optimized starting from the commercially available para-chlorocinnamic acid to give $11,{ }^{20}$ the $\mathrm{N}$-oxide moiety of which was removed by treatment with trimethyl phosphite ${ }^{21}$ (Scheme 1a).

(a)

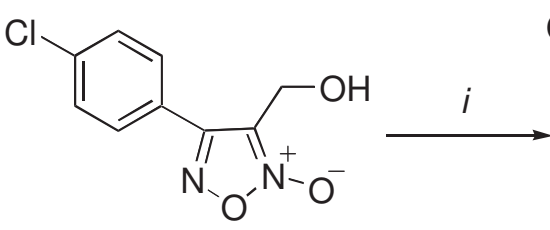

11<smiles>OCc1nonc1-c1ccc(Cl)cc1</smiles>

12

(b)

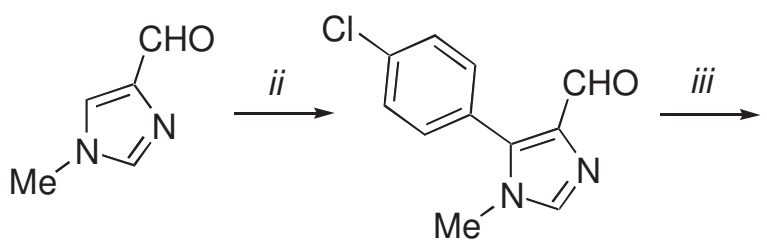

13

14<smiles>Cn1cnc(CO)c1-c1ccc(Cl)cc1</smiles>

15

Scheme 1. Reagents and conditions: (a) i) $\mathrm{P}\left(\mathrm{OCH}_{3}\right)_{3}$, reflux, $18 \mathrm{~h}$; (b): ii) 4- $\mathrm{ClC}_{6} \mathrm{H}_{4} \mathrm{Br}, \mathrm{Pd}(\mathrm{OAc})_{2}, \mathrm{P}(2 \text {-furyl })_{3}$, $\mathrm{K}_{2} \mathrm{CO}_{3}, \mathrm{DMF}, 110^{\circ} \mathrm{C}, 48 \mathrm{~h}$; iii) $\mathrm{NaBH}_{4}, \mathrm{MeOH}, \mathrm{rt}, 4 \mathrm{~h}$.

Compound 15 was prepared from $1 \mathrm{H}$-imidazole-4-carbaldehyde, protected as $\mathrm{N}$-methyl derivative by iodomethane $^{22}(\mathbf{1 3})$, then transformed into 14 through a selective palladium-catalyzed $\mathrm{C}-\mathrm{H}$ activation in position $5 .^{23}$ The subsequent reduction step afforded the desired product 15 in good yield (Scheme $1 \mathrm{~b}$ ).

The intermediates 23, $\mathbf{2 5}$ and $\mathbf{2 7}$ were synthesized from the appropriate benzaldehyde with some variations on the multi-step procedure previously reported ${ }^{16}$ (Scheme 2). Since prolonged (12 hours) treatment in refluxing aqueous $\mathrm{NaOH}$ of 20 a caused an approximately $50 \%$ removal of the Boc (tertbutyloxycarbonyl) group, an additional treatment with tert-butyloxycarbonyl anhydride $\left(\mathrm{Boc}_{2} \mathrm{O}\right)$ was required to give 21a. The amides $\mathbf{2 2}$ and $\mathbf{2 4}$ were obtained by coupling reactions of intermediates $\mathbf{2 1 a , b}$ with 4 (trifluoromethyl)benzoyl chloride, respectively, while the reaction of compound 21c with 4-nitrobenzoyl chloride gave 26. 
Deprotection of $\mathbf{2 2}$ in acidic conditions led to 23; compound $\mathbf{2 4}$ was debenzylated by a catalytic hydrogenation over Pd/C to 25; compound 26 was reduced in the presence of tin(II) chloride to 27.
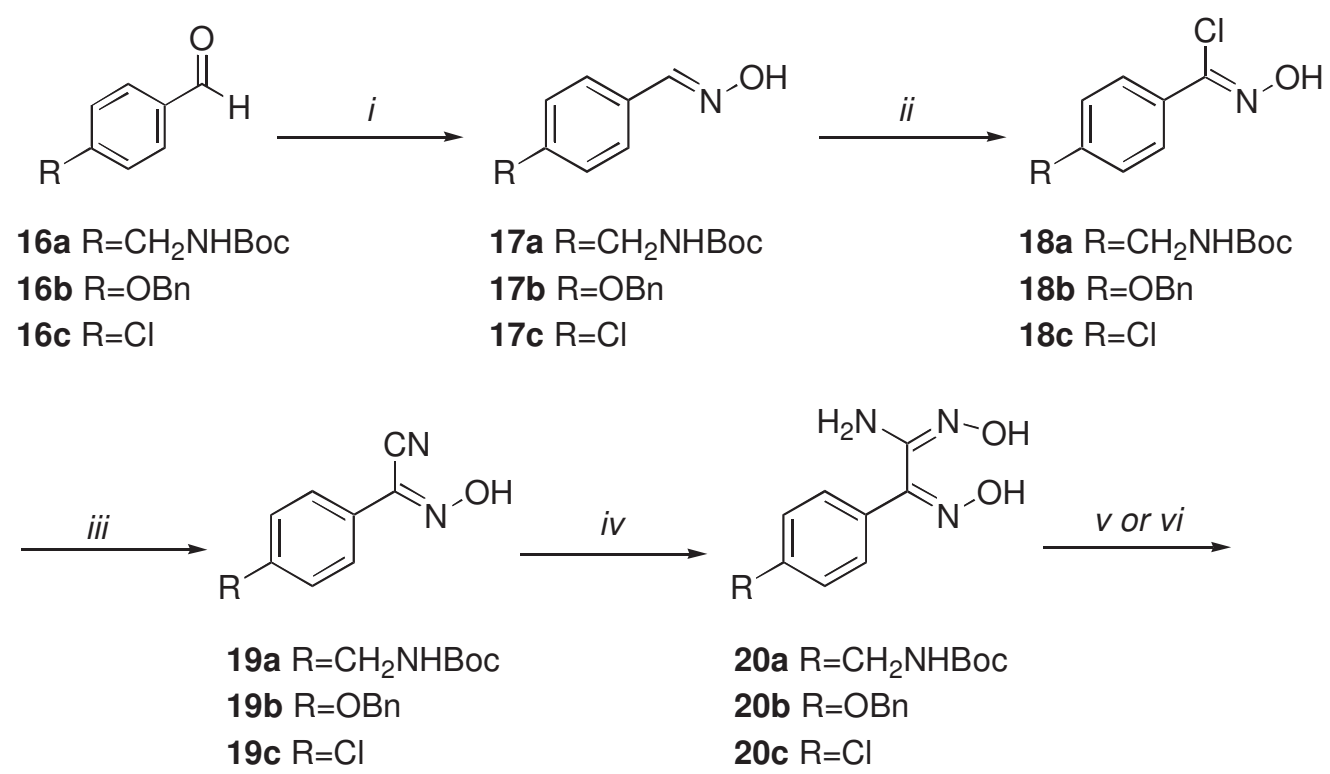

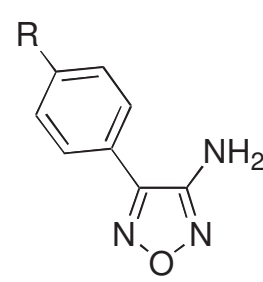

21a $\mathrm{R}=\mathrm{CH}_{2} \mathrm{NHBoc}$

21b $\mathrm{R}=\mathrm{OBn}$

21c $\mathrm{R}=\mathrm{Cl}$

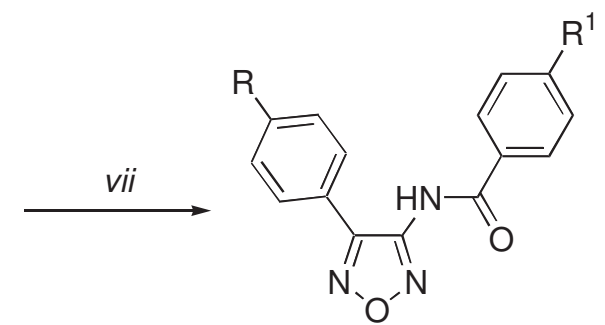

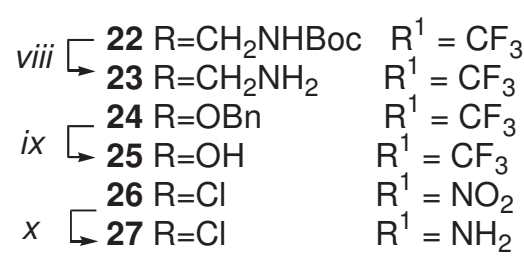

Scheme 2. Reagents and conditions: i) $\mathrm{NH}_{2} \mathrm{OH} \cdot \mathrm{HCl}, \mathrm{NaHCO}_{3}, \mathrm{MeOH}$, reflux, $2 \mathrm{~h}$; ii) NCS, DMF, rt, 12 h;

iii) $\mathrm{KCN}, \mathrm{Et}_{2} \mathrm{O} / \mathrm{H}_{2} \mathrm{O}(2: 1)$, rt, $5 \mathrm{~h}$; iv) $\mathrm{NH}_{2} \mathrm{OH} \cdot \mathrm{HCl}, \mathrm{NaHCO}_{3} \mathrm{MeOH}$, reflux, 12 h; v) $2 \mathrm{~N} \mathrm{NaOH}$, reflux, $12 \mathrm{~h} ;$ vi) a. $2 \mathrm{~N}$ $\mathrm{NaOH}$, reflux, 12 h; b. $\mathrm{Boc}_{2} \mathrm{O}, \mathrm{DCM}, \mathrm{NEt}_{3}, \mathrm{rt}, 4 \mathrm{~h}$; vii) appropriately substituted benzoyl chloride, $60 \% \mathrm{NaH}, \mathrm{dry}$ DMF, $60{ }^{\circ} \mathrm{C}, 12 \mathrm{~h}$; viii) HCl, dry 1,4-dioxane, rt, 10 min; ix) $\mathrm{H}_{2}$, Pd/C, EtOAc/MeOH (9:1), 24 h; x) SnCl, $\mathrm{EtOAc}$ reflux, $4 \mathrm{~h}$.

The final products 1-8 were prepared by condensation of the suitable intermediate with $\mathbf{9}$ (Scheme 3) or 10 (Schemes 4, 5), using different coupling reagents.

The DTT products 1-3 were obtained in good yields (59-78\%) and were easily isolated and purified, thanks to their stability and low solubility.

More difficulties during purification were encountered with all MTS derivatives, which were obtained with moderate $(28-48 \%)$ or low yields (6-7\%). 


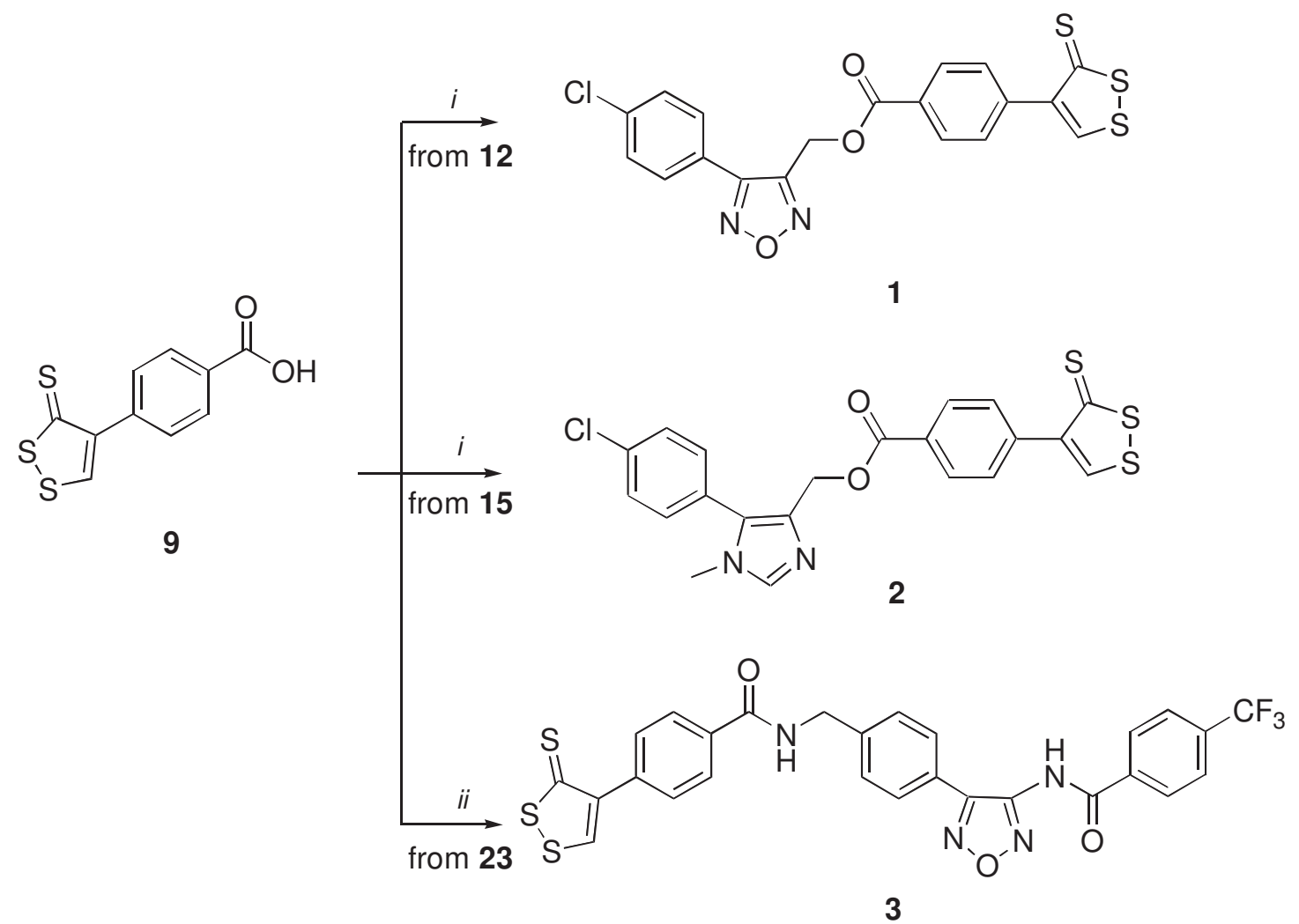

Scheme 3. Reagents and conditions: i) EDC*HCl, DMAP, dry DMF, rt, 24 h or 20 h; ii) TBTU, NMM, dry DMF, $\mathrm{rt}, 20 \mathrm{~h}$.

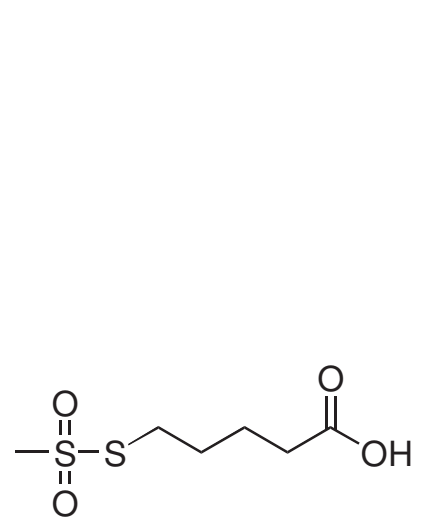

10
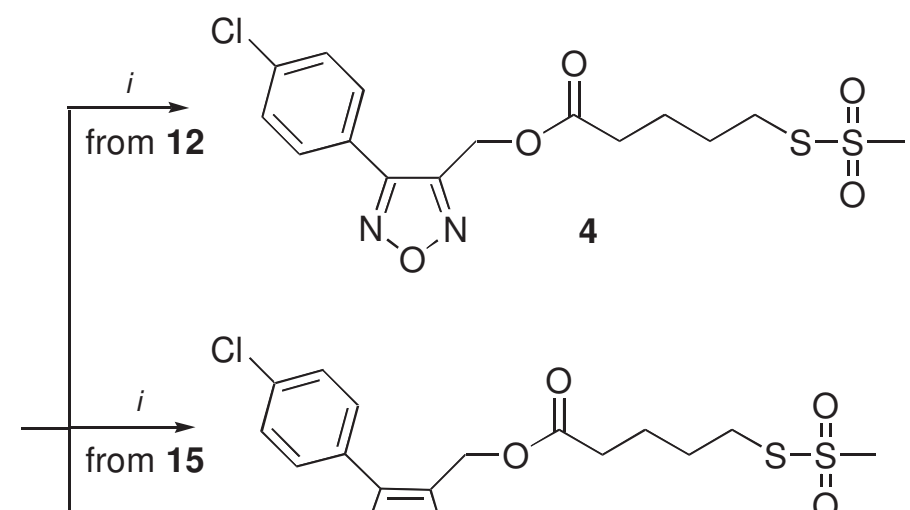

$\mathrm{Cl}$<smiles>Cc1ccc(-c2c(COC(=O)CCCCSS(C)(=O)=O)ncn2C)cc1</smiles><smiles>CCCOCCO</smiles>

Scheme 4. Reagents and conditions: i) DCC, DMAP, dry $\mathrm{CH}_{2} \mathrm{Cl}_{2}$ or dry DMF, rt, 20 h; ii) TBTU, NMM, dry DMF, rt, overnight. 


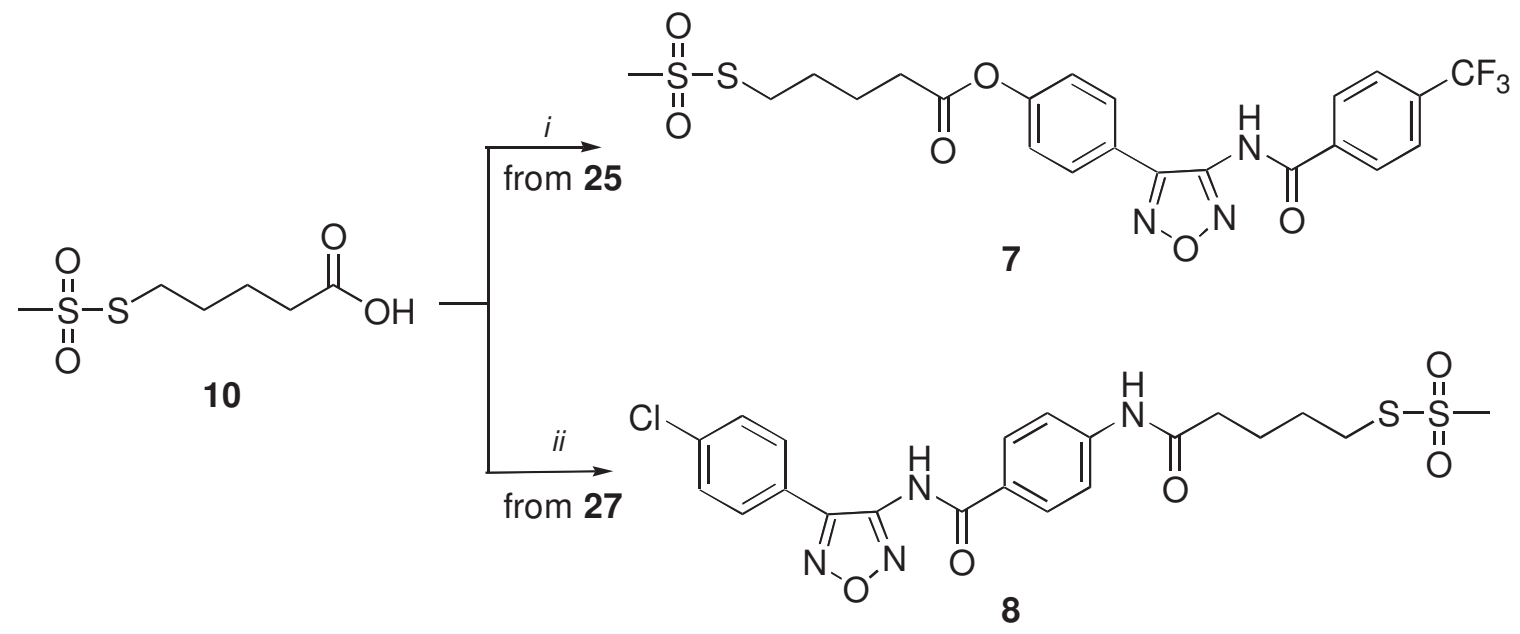

Scheme 5. Reagents and conditions: i) DCC, DMAP, dry THF, rt, 4 h; ii) EDC*HCl, DMAP, dry DMF, rt, 24 h.

\section{Biology}

The effects of the final compounds on STAT3 dimerization were determined by the AlphaScreen-based assay, ${ }^{24}$ an in vitro competitive binding test used to identify compounds able to directly inhibit the binding of SH2containing proteins to their correspondent phosphopeptides. To check the selectivity on STAT3, the new products were tested also on the highly homologous (78\%) STAT1.

The results showed that MTS derivatives strongly interacted with SH2 domain. Of note, compounds 4 and 7 inhibited STAT3 dimerization with an $\mathrm{IC}_{50}$ value of $0.6 \pm 0.05 \mu \mathrm{M}$, though their selectivity versus STAT1 was low $\left(\mathrm{IC}_{50}=5.8 \pm 0.3 \mu \mathrm{M}\right.$ and $7.5 \pm 0.4 \mu \mathrm{M}$, respectively). By contrast, the equipotent $6\left(\mathrm{IC}_{50}=0.7 \pm 0.04 \mu \mathrm{M}\right.$ versus STAT3) was provided with interesting selectivity ( $\mathrm{IC}_{50}>30 \mu \mathrm{M}$ versus STAT1). The corresponding DTTs (1-3) possessed lower affinity (58.7, 26.6 and $33.4 \%$ of inhibition at $30 \mu \mathrm{M}$, respectively), independently from the nature of the linked heterocyclic scaffold.

In addition, their cytotoxic activity (MTT assay) ${ }^{25,26}$ was tested on HCT116, a human colon carcinoma cell line which expresses high levels of STAT3. ${ }^{27}$ Among the assayed compounds, 6 was the most active $\left(\right.$ IC $_{50}=$ 84.5 $\pm 9.8 \mu \mathrm{M})$. Since STAT3 inhibition was tested in a cell-free assay, the low correspondence between STAT3 inhibition and cytotoxicity could be related to the physicochemical properties of the compounds, which will require optimization.

Based on these data, the MTS moiety appears worth of further investigation for targeting STAT3-SH2 domain.

\section{Conclusion}

In our paper, we describe an easy and direct synthetic approach for the preparation of DTT and MTS derivatives, bearing a 1,2,5-oxadiazole ring, which has been reported as a promising scaffold for STAT3 inhibitors. The bioisosteric replacement of the oxadiazole with an $\mathrm{N}$-methylimidazole ring was also considered. Due to their better stability, the DTTs (1-3) were obtained in higher yields than the MTSs (4-8).

The binding efficiency towards STAT3 and STAT1 SH2 domain was evaluated by means of AlphaScreenbased experiments. In addition, their antiproliferative activity was investigated on HCT116 cancer cell line. The biological results showed that MTSs interacted more strongly with $\mathrm{SH} 2$ domain with respect to the 
corresponding DTTs. Although we presume that MTS derivatives can react more easily than DTTs with the free thiol group of cysteine residues present in the protein, further studies are required to elucidate the real mechanism of inhibition and the different reactivities of MTSs and DTTs.

In particular, compound 6 showed a higher affinity and selectivity (STAT3 versus STAT1), together with a moderate cytotoxic activity. These data suggest that MTS derivatives are promising ligands of the STAT3-SH2 domain. Optimization of their physicochemical properties is still needed to increase their cytotoxicity.

\section{Experimental Section}

General. Reagents and solvents were purchased from Sigma-Aldrich and used without further purification. Reactions involving air-sensitive reagents were performed under nitrogen atmosphere and anhydrous solvents were used when necessary. Reactions were monitored by thin layer chromatography analysis on aluminumbacked Silica Gel 60 plates (70-230 mesh, Merck), using an ultraviolet fluorescent lamp at $254 \mathrm{~nm}$ and $365 \mathrm{~nm}$. Visualization was aided by appropriate staining reagents. Purification of intermediates and final compounds was performed by flash chromatography using Geduran ${ }^{\circledR}$ Si 60 (40-63 $\mu \mathrm{m}$, Merck). DMEM (Dulbecco's Modified Eagle Medium), trypsin-EDTA, penicillin, streptomycin, non-essential amino acid solution, fetal calf serum (FCS), disposable culture flasks and petri dishes were purchased from Euroclone S.p.A. (Pero, Milan, Italy).

${ }^{1} \mathrm{H}$ and ${ }^{13} \mathrm{C}$ NMR spectra were recorded in $\mathrm{CDCl}_{3}, \mathrm{CD}_{3} \mathrm{OD}, \mathrm{D}_{2} \mathrm{O}$, DMSO- $d_{6}$ or acetone- $d_{6}$ on Bruker DRX Avance $300 \mathrm{MHz}$ or on a Varian $300 \mathrm{MHz}$ Oxford equipped with a non-reverse probe at $25{ }^{\circ} \mathrm{C}$. Chemical shifts are expressed as $\delta$ (ppm) and were referenced to residual solvent proton/carbon peak. Multiplicity is reported as $s$ (singlet), broad $s$ (broad singlet), $d$ (double), $t$ (triplet), $q$ (quartet), $m$ (multiplet), $d d$ (double of doublets), $d t$ (doublet of triplets). The coupling constants (J-values) are given in Hertz ( $\mathrm{Hz})$. All spectroscopic data match the assigned structures. ESI-MS analyses were performed by using a Thermo Finnigan (MA, USA) LCQ Advantage system MS spectrometer with an electronspray ionization source and an 'Ion Trap' mass analyzer. The MS spectra were obtained by direct infusion of a sample solution in methanol under ionization, ESI positive. Highresolution mass spectra (HRMS) were performed by FT-Orbitrap mass spectrometer in positive electrospray ionization (ESI). The melting points were determined on a Buchi Melting Point B540 instrument.

\section{General procedures for the synthesis of dithiolethiones (1-3) and methanethiosulfonates (4-8)}

Procedure A. Compound 12, 15 or 27 (0.1 mmol), N-(3-dimethylaminopropyl)- $N$ '-ethylcarbodiimide hydrochloride $\left(E D{ }^{*} \mathrm{HCl}, 0.15 \mathrm{mmol}\right)$ and 4-dimethylaminopyridine (DMAP, $\left.0.02 \mathrm{mmol}\right)$ were mixed together in anhydrous $N, N$-dimethylformamide $(1 \mathrm{~mL})$ and the relevant sulfurated compound $\left(\mathbf{9}^{18}\right.$ or $\left.10^{19}, 0.11 \mathrm{mmol}\right)$ was added. The reaction mixture was stirred for $24 \mathrm{~h}$, at rt under an inert atmosphere. The solvent was stripped off and the obtained residue was diluted with EtOAc and washed with a cold solution of $0.5 \mathrm{~N} \mathrm{HCl}$ and then with a cold solution of $5 \% \mathrm{NaHCO}_{3}$, cold water and brine. The organic layer was dried with anhydrous $\mathrm{Na}_{2} \mathrm{SO}_{4}$, filtered and evaporated to dryness to get a residue that was purified by flash chromatography (eluent as indicated for each compound).

Procedure B. The appropriate alcohol (12, 15 and 25, $0.13 \mathrm{mmol}), N, N$-dicyclohexylcarbodiimide (DCC, 0.14 mmol) and DMAP (0.01 mmol) were mixed in anhydrous DMF and 5-(methylsulfonylthio)pentanoic acid (10, ${ }^{19}$ $0.14 \mathrm{mmol}$ ) was added. The reaction mixture was stirred for 4 or $20 \mathrm{~h}$ depending on the involved alcohol derivative, at rt under inert atmosphere. After completion, the formed $N, N^{\prime}$-dicyclohexylurea was filtered off and the solvent was evaporated. The obtained residue was than dissolved in $\mathrm{EtOAc}$ or $\mathrm{CH}_{2} \mathrm{Cl}_{2}$ and washed with 
a cold solution of $0.5 \mathrm{~N} \mathrm{HCl}$, afterward with a cold solution of $5 \% \mathrm{NaHCO}_{3}$, then with cold water and brine. The organic layer was dried with anhydrous $\mathrm{Na}_{2} \mathrm{SO}_{4}$, filtered and evaporated to dryness to get a residue that was purified by flash chromatography or preparative silica-TLC (eluent as indicated for each compound).

Procedure C. Compound $23(0.08 \mathrm{mmol})$ and the correspondent sulfurated compound $\left(\mathbf{9}^{18}\right.$ or $\left.10^{19}, 0.09 \mathrm{mmol}\right)$ were mixed together in anhydrous $N, N$-dimethylformamide $(1 \mathrm{~mL})$ under inert atmosphere. After cooling to $0{ }^{\circ} \mathrm{C}, \quad \mathrm{N}, \mathrm{N}, \mathrm{N}^{\prime}, \mathrm{N}^{\prime}$-Tetramethyl-O-(benzotriazol-1-yl)uronium tetrafluoroborate (TBTU, $0.1 \mathrm{mmol}$ ) and $\mathrm{N}$ methylmorpholine (NMM, $0.08 \mathrm{mmol}$ ) were added and the reaction mixture was stirred for $24 \mathrm{~h}$ at rt. After evaporation of the solvent, the residue was taken up with $\mathrm{CH}_{2} \mathrm{Cl}_{2}$ or EtOAc and washed with a cold solution of $0.5 \mathrm{~N} \mathrm{HCl}$, a cold solution of $5 \% \mathrm{NaHCO}_{3}$, cold water and brine. The organic layer was dried with anhydrous $\mathrm{Na}_{2} \mathrm{SO}_{4}$, filtered and evaporated to dryness. The obtained solid residue was then rinsed and recrystallized with the solvent indicated for each compound.

[4-(4-Chlorophenyl)-1,2,5-oxadiazol-3-yl]methyl 4-(3-thioxo-3H-1,2-dithiol-4-yl)benzoate (1) was synthesized according to procedure A using 4-(3-thioxo-3H-1,2-dithiol-4-yl)benzoic acid (9) and (4-(4-chlorophenyl)-1,2,5oxadiazol-3-yl)methanol (12) in $\mathrm{N}, \mathrm{N}$-dimethylformamide. The obtained residue was purified by column chromatography (silica gel; $\mathrm{CH}_{2} \mathrm{Cl}_{2}$; isocratic). The fractions containing the purified product were gathered up and the amorphous solid obtained was crystallized with petroleum ether $/ \mathrm{CH}_{2} \mathrm{Cl}_{2}$ (2:0.5) and rinsed with the same bland to provide the title compound as an orange crystal solid. Yield: $63 \%$. mp 135.2-134.5 ${ }^{\circ} \mathrm{C} .{ }^{1} \mathrm{H}$ NMR $\left(300 \mathrm{MHz}, \mathrm{CDCl}_{3}\right): \delta_{\mathrm{H}} 8.47(1 \mathrm{H}, \mathrm{s}, \mathrm{CH}=\mathrm{C}), 8.02\left(2 \mathrm{H}, \mathrm{d},{ }^{3} \mathrm{~J}_{\mathrm{HH}} 8.2 \mathrm{~Hz}, \mathrm{CH}\right.$ aromatic) $7.72\left(2 \mathrm{H}, \mathrm{d}^{3}{ }^{3} \mathrm{JH}^{8} 8.2 \mathrm{~Hz}, \mathrm{CH}\right.$ aromatic), $7.62\left(2 \mathrm{H}, \mathrm{d},{ }^{3} \mathrm{~J}_{\mathrm{HH}} 8.2 \mathrm{~Hz}, \mathrm{CH}\right.$ aromatic), $7.48\left(2 \mathrm{H}, \mathrm{d},{ }^{3} \mathrm{~J}_{\mathrm{HH}} 8.2 \mathrm{~Hz}, \mathrm{CH}\right.$ aromatic), $5.65\left(2 \mathrm{H}, \mathrm{s}, \mathrm{CH}_{2}\right) \mathrm{ppm}$. ${ }^{13} \mathrm{C}$ NMR $\left(75 \mathrm{MHz}, \mathrm{DMSO}-\mathrm{d}_{6}\right): \delta_{\mathrm{C}} 214.05,165.24,161.11,153.71,151.14,147.29,139.37,136.64,130.93$, $130.12,129.95,129.82,128.94,124.35,56.65 \mathrm{ppm}$. HRMS (ESI): $\mathrm{m} / z$ calcd for $\mathrm{C}_{19} \mathrm{H}_{12} \mathrm{ClN}_{2} \mathrm{O}_{3} \mathrm{~S}_{3}[\mathrm{M}+\mathrm{H}]^{+}:$ 446.9693; found 446.9691.

[5-(4-Chlorophenyl)-1-methyl-1H-imidazol-4-yl]methyl 4-(3-thioxo-3H-1,2-dithiol-4-yl)-benzoate (2) was synthesized according to procedure A using 4-(3-thioxo-3H-1,2-dithiol-4-yl)benzoic acid (9) and (5-(4chlorophenyl)-1-methyl-1H-imidazol-4-yl)methanol (15). The crude product was purified by flash chromatography (silica gel; $\mathrm{CH}_{2} \mathrm{Cl}_{2} / \mathrm{MeOH}$; in gradient); the product was eluted with $0.8 \%$ of $\mathrm{MeOH}$. The obtained amorphous solid was crystallized with $\mathrm{EtOAc} \mathrm{Et}_{2} \mathrm{O}(0.3: 1)$ and rinsed with the same mixture to reach the final product obtained as an orange crystalline solid. Yield: 59\%. mp 149.9-152.1 ${ }^{\circ} \mathrm{C} .{ }^{1} \mathrm{H} \mathrm{NMR}(300 \mathrm{MHz}$, $\left.\mathrm{CDCl}_{3}\right): \delta_{\mathrm{H}} 8.45(1 \mathrm{H}, \mathrm{s}, \mathrm{CH}=\mathrm{C}), 8.07\left(2 \mathrm{H}, \mathrm{d}^{3}{ }^{3} \mathrm{~J}_{\mathrm{HH}} 8.8 \mathrm{~Hz}, \mathrm{CH}\right.$ aromatic), 7.59-7.55 (3H, m, CH aromatic), $7.43(2 \mathrm{H}$, d, ${ }^{3} \mathrm{~J}_{\mathrm{HH}} 8.8 \mathrm{~Hz}, \mathrm{CH}$ aromatic), $7.30\left(2 \mathrm{H}, \mathrm{d},{ }^{3} \mathrm{~J}_{\mathrm{HH}} 8.5 \mathrm{~Hz}, \mathrm{CH}\right.$ aromatic), $5.22\left(2 \mathrm{H}, \mathrm{s}, \mathrm{CH}_{2}\right), 3.57\left(3 \mathrm{H}, \mathrm{s}, \mathrm{CH}_{3}\right) \mathrm{ppm} .{ }^{13} \mathrm{C}$ NMR $\left(75 \mathrm{MHz}\right.$, DMSO-d 6 ): $\delta_{\mathrm{C}}$ 214.10, 165.76, 165.76, 160.97, 147.48, 138.83, 134.07, 133.89, 132.07, 131.26, $130.12,129.86,129.65,129.51,128.32,61.15,32.84 \mathrm{ppm}$. HRMS(ESI): $\mathrm{m} / z$ calcd for $\mathrm{C}_{21} \mathrm{H}_{16} \mathrm{CIN}_{2} \mathrm{O}_{2} \mathrm{~S}_{3}[\mathrm{M}+\mathrm{H}]^{+}$: 459.0062; found 459.0055.

\section{[4-(3-Thioxo-3H-1,2-dithiol-4-yl)-N-(4-\{4-[4-(trifluoromethyl)benzamido]-1,2,5-oxadiazol-3-}

yl\}benzyl)benzamide (3) was synthesized according to procedure $\mathbf{C}$ using 4-(3-thioxo-3H-1,2-dithiol-4$\mathrm{yl}$ )benzoic acid (9). The crude product was rinsed three times with a solution of $\mathrm{Et}_{2} \mathrm{O} / \mathrm{CH}_{2} \mathrm{Cl}_{2}(1: 1)$ and it was isolated as an orange solid. Yield: $78 \% . \mathrm{mp} 119.2-124.5^{\circ} \mathrm{C} .{ }^{1} \mathrm{H} N M R\left(300 \mathrm{MHz}\right.$, acetone- $\left.d_{6}\right): \delta_{\mathrm{H}} 10.58(1 \mathrm{H}$, broad s, NH exchanged with $\left.\mathrm{D}_{2} \mathrm{O}\right), 9.10(1 \mathrm{H}, \mathrm{s}, \mathrm{CH}=\mathrm{C}), 8.41\left(1 \mathrm{H}\right.$, broad s, NH exchanged with $\left.\mathrm{D}_{2} \mathrm{O}\right), 8.24\left(2 \mathrm{H}, \mathrm{d},{ }^{3} \mathrm{~J}_{\mathrm{HH}} 8.4\right.$ $\mathrm{Hz}, \mathrm{CH}$ aromatic), $8.00\left(2 \mathrm{H}, \mathrm{d},{ }^{3} \mathrm{~J}_{\mathrm{HH}} 8.6 \mathrm{~Hz}, \mathrm{CH}\right.$ aromatic), $7.91\left(2 \mathrm{H}, \mathrm{d},{ }^{3} \mathrm{~J}_{\mathrm{HH}} 8.4 \mathrm{~Hz}, \mathrm{CH}\right.$ aromatic), $7.81\left(2 \mathrm{H}, \mathrm{d},{ }^{3} \mathrm{~J}_{\mathrm{HH}}\right.$ $8.6 \mathrm{~Hz}, \mathrm{CH}$ aromatic), $7.72\left(2 \mathrm{H}, \mathrm{d},{ }^{3} \mathrm{~J}_{\mathrm{HH}} 8.2 \mathrm{~Hz}, \mathrm{CH}\right.$ aromatic), $7.52\left(2 \mathrm{H}, \mathrm{d},{ }^{3} \mathrm{~J}_{\mathrm{HH}} 8.4 \mathrm{~Hz}, \mathrm{CH}\right.$ aromatic), $4.68(2 \mathrm{H}, \mathrm{d}$, $\left.{ }^{2} J_{\mathrm{HH}} 4.2 \mathrm{~Hz}, \mathrm{CH}_{2}\right) \mathrm{ppm} .{ }^{13} \mathrm{C} \mathrm{NMR}\left(75 \mathrm{MHz}\right.$, acetone- $\left.d_{6}\right): \delta_{\mathrm{C}} 214.20,166.06,157.71,151.40,149.61,147.73$, $142.70,136.25,134.61,129.02,128.90,128.03,127.61,127.36,127.08,125.70,124.58,124.21,119.07$, 109.40, 42.68 ppm. HRMS (ESI): $m / z$ calcd for $\mathrm{C}_{27} \mathrm{H}_{18} \mathrm{~F}_{3} \mathrm{~N}_{4} \mathrm{O}_{3} \mathrm{~S}_{3}[\mathrm{M}+\mathrm{H}]^{+}:$:599.0493; found 599.0497. 
[4-(4-Chlorophenyl)-1,2,5-oxadiazol-3-yl]methyl 5-(methylsulfonylthio)pentanoate (4) was synthesized according to procedure $\mathbf{B}$ using [4-(4-chlorophenyl)-1,2,5-oxadiazol-3-yl]methanol (12), dissolved in anhydrous $\mathrm{CH}_{2} \mathrm{Cl}_{2}$. The reaction was stirred for $20 \mathrm{~h}$. The crude product was purified by preparative silica-TLC using $\mathrm{CH}_{2} \mathrm{Cl}_{2} / \mathrm{MeOH}(96: 4)$ as eluent mixture. The title compound was obtained as a colorless oil. Yield: $35 \%$. ${ }^{1} \mathrm{H} \mathrm{NMR}$ (300 MHz, CDCl 3$): \delta_{\mathrm{H}} 7.65\left(2 \mathrm{H}, \mathrm{d},{ }^{3} J_{\mathrm{HH}} 9 \mathrm{~Hz}, \mathrm{CH}\right.$ aromatic), $7.51\left(2 \mathrm{H}, \mathrm{d},{ }^{3} J_{\mathrm{HH}} 8.7 \mathrm{~Hz}, \mathrm{CH}\right.$ aromatic), $5.40(2 \mathrm{H}, \mathrm{s}$, $\left.\mathrm{CH}_{2}\right), 3.31\left(3 \mathrm{H}, \mathrm{s}, \mathrm{CH}_{3}\right), 3.14\left(2 \mathrm{H}, \mathrm{t},{ }^{3} \mathrm{~J}_{\mathrm{HH}} 7.3 \mathrm{~Hz}, \mathrm{CH}_{2} \mathrm{COO}\right), 2.39\left(2 \mathrm{H}, \mathrm{t},{ }^{3} \mathrm{JHH}_{\mathrm{HH}} 7.3 \mathrm{~Hz}, \mathrm{SCH}_{2}\right), 1.79-1.72\left(4 \mathrm{H}, \mathrm{m}, \mathrm{CH}_{2}\right)$ ppm. ${ }^{13} \mathrm{C} \mathrm{NMR}\left(75 \mathrm{MHz}, \mathrm{CDCl}_{3}\right.$ ): $\delta_{\mathrm{C}} 172.71,135.20,133.62,131.24,129.19,126.69,60.43,59.52,50.74,47.40$, $36.03,33.31,32.55,28.91,23.66$ ppm. HRMS (ESI): $\mathrm{m} / z$ calcd for $\mathrm{C}_{15} \mathrm{H}_{21} \mathrm{ClN}_{3} \mathrm{O}_{5} \mathrm{~S}_{2}\left[\mathrm{M}+\mathrm{NH}_{4}\right]^{+}:$422.06057; found 422.0606.

[5-(4-Chlorophenyl)-1-methyl-1H-imidazol-4-yl]methyl $\quad 5$-[(methylsulfonyl)thio]pentanoate $\quad$ (5) was synthesized according to procedure B starting from [5-(4-chlorophenyl)-1-methyl-1H-imidazol-4-yl]methanol (15), dissolved in anhydrous $\mathrm{N}, \mathrm{N}$-dimethylformamide. The reaction mixture was stirred for $20 \mathrm{~h}$. The crude product was purified by flash chromatography (silica gel; $\mathrm{CH}_{2} \mathrm{Cl}_{2} / \mathrm{MeOH}$; in gradient); the product was eluted with $0.1 \%$ of $\mathrm{MeOH}$. The product was collected as a pale yellow-green oil. Yield: $28 \% .{ }^{1} \mathrm{H}-\mathrm{NMR}(300 \mathrm{MHz}$, $\left.\mathrm{CDCl}_{3}\right): \delta_{\mathrm{H}} 7.45\left(2 \mathrm{H}, \mathrm{d},{ }^{3} \mathrm{~J}_{\mathrm{HH}} 8.7 \mathrm{~Hz}, \mathrm{CH}\right.$ aromatic), $7.30\left(2 \mathrm{H}, \mathrm{d},{ }^{3} \mathrm{~J}_{\mathrm{HH}} 9 \mathrm{~Hz}, \mathrm{CH}\right.$ aromatic), $5.28\left(2 \mathrm{H}, \mathrm{s}, \mathrm{CH}_{2}\right), 3.58(3 \mathrm{H}$, $\left.\mathrm{s}, \mathrm{CH}_{3}\right), 3.31\left(3 \mathrm{H}, \mathrm{s}, \mathrm{SO}_{2} \mathrm{CH}_{3}\right), 3.14\left(2 \mathrm{H}, \mathrm{t},{ }^{3} \mathrm{~J}_{\mathrm{HH}} 6.9 \mathrm{~Hz}, \mathrm{CH}_{2} \mathrm{COO}\right), 2.39\left(2 \mathrm{H}, \mathrm{t},{ }^{3} \mathrm{JHH}_{\mathrm{HH}} 6.9 \mathrm{~Hz}, \mathrm{SCH}_{2}\right), 1.79-1.72(4 \mathrm{H}, \mathrm{m}$, $\mathrm{CH}_{2}$ ) ppm. ${ }^{13} \mathrm{C}$ NMR $\left(75 \mathrm{MHz}, \mathrm{CDCl}_{3}\right): \delta_{\mathrm{C}} 171.89,148.95,137.35,129.68,129.49,123.66,54.88,50.70,35.81$, 32.96, 29.69, 28.90, 23.40 ppm. HRMS(ESI): $\mathrm{m} / z$ calcd for $\mathrm{C}_{17} \mathrm{H}_{21} \mathrm{~N}_{2} \mathrm{O}_{4} \mathrm{~S}_{2} \mathrm{ClNa}[\mathrm{M}+\mathrm{Na}]^{+}:$439.0523; found 439.0531.

S-5-0xo-5-(4-\{4-[4-(trifluoromethyl)benzamido]-1,2,5-oxadiazol-3-yl\}benzylamino)pentyl methanesulfonothioate (6) was synthesized according to procedure C using 5-(methylsulfonylthio)pentanoic acid (10). The crude was rinsed three times with pure ethyl ether to give the final product as white-cream crystals. Yield: 42\%. mp 179.4-181.3 ${ }^{\circ} \mathrm{C} .{ }^{1} \mathrm{H}$ NMR (300 MHz, acetone- $\left.d_{6}\right): \delta_{\mathrm{H}} 10.55\left(1 \mathrm{H}\right.$, broad s, NH exchanged with $\left.\mathrm{D}_{2} \mathrm{O}\right), 8.25$ $\left(2 \mathrm{H}, \mathrm{d},{ }^{3} \mathrm{~J}_{\mathrm{HH}} 8.4 \mathrm{~Hz}, \mathrm{CH}\right.$ aromatic), $7.93\left(2 \mathrm{H}, \mathrm{d},{ }^{3} \mathrm{~J}_{\mathrm{HH}} 8.1 \mathrm{~Hz}, \mathrm{CH}\right.$ aromatic), $7.78\left(2 \mathrm{H}, \mathrm{d},{ }^{3} \mathrm{~J}_{\mathrm{HH}} 8.1 \mathrm{~Hz}, \mathrm{CH}\right.$ aromatic), $7.61\left(1 \mathrm{H}\right.$, broad s, NH exchanged with $\left.\mathrm{D}_{2} \mathrm{O}\right), 7.42\left(2 \mathrm{H}, \mathrm{d},{ }^{3} \mathrm{~J}_{\mathrm{HH}} 8.4 \mathrm{~Hz}, \mathrm{CH}\right.$ aromatic $), 4.43\left(2 \mathrm{H}, \mathrm{d},{ }^{2} \mathrm{JHH}_{\mathrm{HH}} 6.0 \mathrm{~Hz}, \mathrm{CH}_{2}\right)$, $3.41\left(3 \mathrm{H}, \mathrm{s}, \mathrm{CH}_{3}\right), 3.23\left(2 \mathrm{H}, \mathrm{t},{ }^{3} \mathrm{~J}_{\mathrm{HH}} 6.9 \mathrm{~Hz}, \mathrm{CH}_{2} \mathrm{COO}\right), 2.30\left(2 \mathrm{H}, \mathrm{t},{ }^{3} \mathrm{~J}_{\mathrm{HH}} 6.9 \mathrm{~Hz}, \mathrm{CH}_{2} \mathrm{~S}\right), 1.84-1.71\left(4 \mathrm{H}, \mathrm{m}, \mathrm{CH}_{2}\right) \mathrm{ppm}$. ${ }^{13} \mathrm{C}$ NMR $\left(75 \mathrm{MHz}\right.$, acetone- $\left.d_{6}\right): \delta_{\mathrm{C}} 171.82,165.22,151.42,149.73,142.86,136.27,134.21,128.91,127.94$, $127.54,125.73,124.17,49.84,42.19,35.60,34.79,28.93,24.24 \mathrm{ppm}$. HRMS (ES $\left.{ }^{+}\right): \mathrm{m} / z$ calcd for $\mathrm{C}_{23} \mathrm{H}_{24} \mathrm{~F}_{3} \mathrm{~N}_{4} \mathrm{O}_{5} \mathrm{~S}_{2}[\mathrm{M}+\mathrm{H}]^{+}:$557.1140; found 557.1132.

4-\{4-[4-(Trifluoromethyl)benzamido]-1,2,5-oxadiazol-3-yl\}phenyl 5-(methylsulfonylthio)pentanoate (7) was synthesized according to procedure B using N-(4-(4-hydroxyphenyl)-1,2,5-oxadiazol-3-yl)-4-(trifluoromethyl) benzamide (25) dissolved in anhydrous tetrahydrofuran. The reaction mixture was stirred for $4 \mathrm{~h}$. The product was purified by flash chromatography (silica gel; EtOAc/cyclohexane in ratio 8:2; isocratic). The fractions containing the purified product were gathered up to provide a white solid. Yield: $48 \% . \mathrm{mp} 157.1-158.6{ }^{\circ} \mathrm{C} .{ }^{1} \mathrm{H}$ NMR $\left(300 \mathrm{MHz}\right.$, acetone- $\left.d_{6}\right): \delta_{\mathrm{H}} 10.59\left(1 \mathrm{H}\right.$, broad s, NH exchanged with $\left.\mathrm{D}_{2} \mathrm{O}\right), 8.25\left(2 \mathrm{H}, \mathrm{d}^{3}{ }^{3} \mathrm{JHH} 8.4 \mathrm{~Hz}, \mathrm{CH}\right.$ aromatic), 7.95-7.88 (4H, m, CH aromatic), $7.30\left(2 \mathrm{H}, \mathrm{d},{ }^{3} \mathrm{~J}_{\mathrm{HH}} 8.7 \mathrm{~Hz}, \mathrm{CH}\right.$ aromatic), $3.44\left(3 \mathrm{H}, \mathrm{s}, \mathrm{CH}_{3}\right), 3.30(2 \mathrm{H}, \mathrm{t}$, $\left.{ }^{3} \mathrm{~J}_{\mathrm{HH}} 7.2 \mathrm{~Hz}, \mathrm{CH}_{2} \mathrm{COO}\right), 2.70\left(2 \mathrm{H}, \mathrm{t},{ }^{3} \mathrm{~J}_{\mathrm{HH}} 7.2 \mathrm{~Hz}, \mathrm{CH}_{2} \mathrm{~S}\right), 2.03-1.82\left(4 \mathrm{H}, \mathrm{m}, \mathrm{CH}_{2}\right) \mathrm{ppm} .{ }^{13} \mathrm{C} \mathrm{NMR}(75 \mathrm{MHz}$, acetone$\left.d_{6}\right): \delta_{C} 170.99,165.24,152.81,150.96,149.95,136.41,128.91,128.89,125.68,123.15,122.58,49.84,35.45$, 32.94, 28.93, 23.35 ppm. HRMS (ESI): $\mathrm{m} / z$ calcd for $\mathrm{C}_{22} \mathrm{H}_{21} \mathrm{~F}_{3} \mathrm{~N}_{3} \mathrm{O}_{6} \mathrm{~S}_{2}[\mathrm{M}+\mathrm{H}]^{+}:$544.0824; found 544.0816.

\section{S-5-\{4-[4-(4-Chlorophenyl)-1,2,5-oxadiazol-3-ylcarbamoyl]phenylamino\}-5-oxopentyl methanesulfono-} thioate (8) was synthesized according to procedure A using 4-amino- $N$-[4-(4-chlorophenyl)-1,2,5-oxadiazol-3yl]benzamide (27) and 5-(methylsulfonylthio)pentanoic acid (10). The crude mixture residue was purified by column chromatography (silica gel; EtOAc/cyclohexane; in gradient); the product was eluted with $40 \%$ of EtOAc. The title compound was obtained as a grey-white solid. Yield: 7\%. mp 194.8-198.1 ${ }^{\circ} \mathrm{C} .{ }^{1} \mathrm{H}$ NMR (300 
$\mathrm{MHz}$, acetone- $\left.d_{6}\right): \delta_{\mathrm{H}} 10.28\left(1 \mathrm{H}\right.$, broad s, $\mathrm{NH}$ exchanged with $\left.\mathrm{D}_{2} \mathrm{O}\right), 9.51\left(1 \mathrm{H}\right.$, broad s, $\mathrm{NH}$ exchanged with $\left.\mathrm{D}_{2} \mathrm{O}\right)$, $8.00\left(2 \mathrm{H}, \mathrm{d},{ }^{3} \mathrm{~J}_{\mathrm{HH}} 8.8 \mathrm{~Hz}, \mathrm{CH}\right.$ aromatic), 7.91-7.80 (4H, m, CH aromatic), $7.55\left(2 \mathrm{H}, \mathrm{d}^{3}{ }^{3} \mathrm{~J}_{\mathrm{HH}} 8.8 \mathrm{~Hz}, \mathrm{CH}\right.$ aromatic), $3.45\left(3 \mathrm{H}, \mathrm{s}, \mathrm{CH}_{3}\right), 3.29\left(2 \mathrm{H}, \mathrm{t},{ }^{3} \mathrm{~J}_{\mathrm{HH}} 6.6 \mathrm{~Hz}, \mathrm{CH}_{2} \mathrm{COO}\right), 2.50\left(2 \mathrm{H}, \mathrm{t},{ }^{3} \mathrm{~J}_{\mathrm{HH}} 6.6 \mathrm{~Hz}, \mathrm{CH}_{2} \mathrm{~S}\right), 1.97-1.84\left(4 \mathrm{H}, \mathrm{m}, \mathrm{CH}_{2}\right) \mathrm{ppm}$. HRMS (ESI): $m / z$ calcd for $\mathrm{C}_{21} \mathrm{H}_{22} \mathrm{ClN}_{4} \mathrm{O}_{5} \mathrm{~S}_{2}[\mathrm{M}+\mathrm{H}]^{+}: 509.0720$; found 509.0712 .

(4-(4-Chlorophenyl)-1,2,5-oxadiazol-3-yl)methanol 2-oxide (11). This intermediate was synthesized according to the procedure reported in literature. ${ }^{20}$ Brown oil. Yield $50 \% .{ }^{1} \mathrm{H} \mathrm{NMR}\left(300 \mathrm{MHz}, \mathrm{CDCl}_{3}\right) \delta_{\mathrm{H}} 7.79\left(2 \mathrm{H}, \mathrm{d},{ }^{3} J_{\mathrm{HH}}\right.$ $8.6 \mathrm{~Hz}, \mathrm{CH}$ aromatic), $7.53\left(2 \mathrm{H}, \mathrm{d},{ }^{3} J_{\mathrm{HH}} 8.6 \mathrm{~Hz}, \mathrm{CH}\right.$ aromatic), $4.73\left(2 \mathrm{H}, \mathrm{s}, \mathrm{CH}_{2}\right) .{ }^{13} \mathrm{C} \mathrm{NMR}\left(75 \mathrm{MHz}^{\mathrm{C}} \mathrm{CDCl}_{3}\right) \delta_{\mathrm{C}}$ $155.81,137.77,129.74,129.06,124.62$, 53.31. MS (ESI) $\mathrm{m} / z$ calcd for $\mathrm{C}_{9} \mathrm{H}_{8} \mathrm{CIN}_{2} \mathrm{O}_{3}[\mathrm{M}+\mathrm{H}]^{+}: 227.02$; found 227.01.

(4-(4-Chlorophenyl)-1,2,5-oxadiazol-3-yl)methanol (12). ${ }^{21}$ Compound 11 (1.26 mmol) was refluxed with trimethylphosphite $(2.62 \mathrm{~mL})$ for $18 \mathrm{~h}$, in a flame-dried flask under nitrogen, monitoring the reaction by TLC (cyclohexane/ $\mathrm{CH}_{2} \mathrm{Cl}_{2} /$ EtOAc 5:4.5:0.5). After cooling, $1 \mathrm{~N} \mathrm{HCl}(26.2 \mathrm{~mL}$ ) was added and the reaction mixture was extracted with $\mathrm{Et}_{2} \mathrm{O}$. The combined organic layers were washed with saturated $\mathrm{NaHCO}_{3}$, and then with brine, dried and evaporated. Flash chromatography (cyclohexane/EtOAc 8:2) was performed to give 12, as yellow oil. Yield $=15 \% .{ }^{1} \mathrm{H}$ NMR $\left(300 \mathrm{MHz}, \mathrm{CDCl}_{3}\right) \delta_{\mathrm{H}} 7.86\left(2 \mathrm{H}, \mathrm{d},{ }^{3} \mathrm{~J}_{\mathrm{HH}} 8.4 \mathrm{~Hz}, \mathrm{CH}\right.$ aromatic $), 7.51\left(2 \mathrm{H}, \mathrm{d},{ }^{3} J_{\mathrm{HH}} 8.4\right.$ $\mathrm{Hz}, \mathrm{CH}$ aromatic), $4.98\left(2 \mathrm{H}, \mathrm{s}, \mathrm{CH}_{2}\right) .{ }^{13} \mathrm{C} \mathrm{NMR}\left(75 \mathrm{MHz}\right.$, acetone-d $\left.\mathrm{d}_{6}\right) \delta_{\mathrm{C}} 153.42,153.21,136.29,130.19,129.28$, 124.73, 52.89. MS (ESI) $\mathrm{m} / z$ calcd for $\mathrm{C}_{9} \mathrm{H}_{7} \mathrm{CIN}_{2} \mathrm{O}_{2} \mathrm{Na}[\mathrm{M}+\mathrm{Na}]^{+}:$233.01; found 233.6.

1-Methyl-1H-imidazole-4-carbaldehyde (13). This intermediate was synthesized according to the procedure reported in literature. ${ }^{22}$ The final product was collected as a pale-yellow solid. Yield $=65 \% .{ }^{1} \mathrm{H} \mathrm{NMR}(300 \mathrm{MHz}$, $\left.\mathrm{CDCl}_{3}\right) \delta_{\mathrm{H}} 9.87(1 \mathrm{H}, \mathrm{s}, \mathrm{CHO}), 7.60\left(1 \mathrm{H}, \mathrm{s}, \mathrm{CH}\right.$ aromatic), $7.57\left(1 \mathrm{H}, \mathrm{s}, \mathrm{CH}\right.$ aromatic), $3.78\left(3 \mathrm{H}, \mathrm{s}, \mathrm{CH}_{3}\right) .{ }^{13} \mathrm{C} \mathrm{NMR}(75$ $\left.\left.\mathrm{MHz}, \mathrm{CDCl}_{3}\right) \delta_{\mathrm{C}} 186.4,142.9,139.5,125.4,34.2 . \mathrm{MS}_{(\mathrm{ES}}{ }^{+}\right): \mathrm{m} / z$ calcd for $\mathrm{C}_{5} \mathrm{H}_{7} \mathrm{~N}_{2} \mathrm{O}[\mathrm{M}+\mathrm{H}]^{+}:$111.06; found 111.1 .

5-(4-Chlorophenyl)-1-methyl-1H-imidazole-4-carbaldehyde (14). ${ }^{23}$ 1-bromo-4-chlorobenzene (1.5 mmol), $\mathrm{Pd}(\mathrm{OAc})_{2}(0.05 \mathrm{mmol}), \mathrm{P}(2 \text {-furyl })_{3}(0.1 \mathrm{mmol})$ and $\mathrm{K}_{2} \mathrm{CO}_{3}(2.0 \mathrm{mmol})$ were placed in a reaction vessel under a stream of nitrogen. Deaerated $13(1.0 \mathrm{mmol})$ and anhydrous $N, N$-dimethylformamide $(5 \mathrm{~mL})$ were then added and the resulting mixture was stirred at $110{ }^{\circ} \mathrm{C}$ for $48 \mathrm{~h}$, monitoring the reaction by $\operatorname{TLC}\left(\mathrm{CH}_{2} \mathrm{Cl}_{2} / \mathrm{MeOH}^{95: 5)}\right.$. Once the reaction was complete, the mixture was cooled to rt, diluted with $\mathrm{EtOAc} / \mathrm{CH}_{2} \mathrm{Cl} 2(1: 1,30 \mathrm{~mL})$, and filtered through Celite. The filtrate was concentrated under reduced pressure and purified by flash chromatography with $\mathrm{CH}_{2} \mathrm{Cl}_{2} / \mathrm{MeOH}$ 95:5 as the eluent. The product was obtained as a pale yellow solid. Yield: 40\%. ${ }^{1} \mathrm{H}$ NMR $\left(300 \mathrm{MHz}, \mathrm{CDCl}_{3}\right) \delta_{\mathrm{H}} 9.80(1 \mathrm{H}, \mathrm{s}, \mathrm{CHO}), 7.62\left(1 \mathrm{H}, \mathrm{s}, \mathrm{CH}\right.$ aromatic), $7.50\left(2 \mathrm{H}, \mathrm{d},{ }^{3} J_{\mathrm{HH}} 8.43 \mathrm{~Hz}, \mathrm{CH}\right.$ aromatic), $7.36\left(2 \mathrm{H}, \mathrm{d},{ }^{3} \mathrm{~J}_{\mathrm{HH}} 8.43 \mathrm{~Hz}, \mathrm{CH}\right.$ aromatic), $3.59\left(3 \mathrm{H}, \mathrm{s}, \mathrm{CH}_{3}\right) \mathrm{ppm} .{ }^{13} \mathrm{C} \mathrm{NMR}\left(75 \mathrm{MHz}, \mathrm{CDCl}_{3}\right) \delta_{\mathrm{C}} 185.36$, $149.25,137.87,131.12,129.54,129.33,128.06,125.98,33.78 \mathrm{ppm}$. MS (ESI): $\mathrm{m} / z$ calcd for $\mathrm{C}_{11} \mathrm{H}_{9} \mathrm{ClN}_{2} \mathrm{NaO}$ $[\mathrm{M}+\mathrm{Na}]^{+}:$243.03; found 243.1 .

[5-(4-Chlorophenyl)-1-methyl-1H-imidazol-4-yl]methanol (15). To a solution of 14 (0.5 mmol) in $\mathrm{MeOH}(5 \mathrm{~mL})$ at $0^{\circ} \mathrm{C}$, sodium borohydride $(0.25 \mathrm{mmol})$ was added. The reaction was warmed to $\mathrm{rt}$ and monitored using TLC analysis (eluent $\mathrm{CH}_{2} \mathrm{Cl}_{2} / \mathrm{MeOH}$ 95:5) until the reaction was complete. The mixture was quenched by adding water $(5 \mathrm{~mL})$ and extracted with $\mathrm{CH}_{2} \mathrm{Cl}_{2}(3 \times 5 \mathrm{~mL})$. The combined organic layers were dried over $\mathrm{Na}_{2} \mathrm{SO}_{4}$, filtered and evaporated under reduced pressure. The desired product was obtained as a pale-yellow solid after crystallization in $\mathrm{CH}_{2} \mathrm{Cl}_{2} / n$-hexane. Yield: $45 \%$. ${ }^{1} \mathrm{H} \mathrm{NMR}\left(300 \mathrm{MHz}, \mathrm{CD}_{3} \mathrm{OD}\right) \delta_{\mathrm{H}} 7.68(1 \mathrm{H}, \mathrm{s}, \mathrm{CH}$ aromatic), 7.49 $\left(4 \mathrm{H}, \mathrm{m}, \mathrm{CH}\right.$ aromatic), $4.39\left(2 \mathrm{H}, \mathrm{s}, \mathrm{CH}_{2}\right), 3.59\left(3 \mathrm{H}, \mathrm{s}, \mathrm{CH}_{3}\right) \mathrm{ppm} .{ }^{13} \mathrm{C} \mathrm{NMR}\left(75 \mathrm{MHz}, \mathrm{CD}_{3} \mathrm{OD}\right) \delta_{\mathrm{C}} 138.23,138.04$, 134.52, 131.53, 130.21, 128.75, 127.80, 56.46, 31.61 ppm. MS $\left(\right.$ ES $\left.^{+}\right): \mathrm{m} / z$ calcd for $\mathrm{C}_{11} \mathrm{H}_{12} \mathrm{ClN}_{2} \mathrm{O}[\mathrm{M}+\mathrm{H}]^{+}: 223.06$; found 223.1.

General procedure for the synthesis of benzaldehyde oximes $(17 \mathrm{a}-\mathrm{c}) . \mathrm{NH}_{2} \mathrm{OH} \cdot \mathrm{HCl}(7.2 \mathrm{mmol})$ and $\mathrm{NaHCO}_{3}$ $(7.2 \mathrm{mmol})$ in water $(9 \mathrm{~mL})$ were added to a solution of the proper aldehyde 16a-c $(6.0 \mathrm{mmol})$ in $\mathrm{MeOH}(18$ $\mathrm{mL}$ ). The mixture was refluxed under stirring for $2 \mathrm{~h}$ and the solvent was evaporated under vacuum. The 
aqueous phase was extracted with EtOAc $(3 \times 10 \mathrm{~mL})$, the organic solvent dried over $\mathrm{Na}_{2} \mathrm{SO}_{4}$ and evaporated under reduced pressure to obtain the oximes (17a-b), which were used in the next reaction without further purification.

tert-Butyl-4-[(hydroxyimino)methyl]benzylcarbamate (17a) was synthesized starting from 16a (prepared according to literature procedure $\left.{ }^{28}\right)$. White solid. Yield $81 \% .{ }^{1} \mathrm{H} \mathrm{NMR}\left(300 \mathrm{MHz}^{\mathrm{CDCl}}\right)_{3} \delta_{H} 8.11(\mathrm{~s}, 1 \mathrm{H}, \mathrm{CH})$, 7.51-7.24 (m, 4H, CH aromatic), 5.27 (broad s, $1 \mathrm{H}$, NH exchanged with $\left.\mathrm{D}_{2} \mathrm{O}\right), 4.32\left(\mathrm{~s}, 2 \mathrm{H}, \mathrm{CH}_{2}\right), 1.47(\mathrm{~s}, 9 \mathrm{H}$, $\left.\mathrm{C}\left(\mathrm{CH}_{3}\right)_{3}\right) \mathrm{ppm}$.

4-Phenoxybenzaldehyde oxime (17b) was synthesized starting from $\mathbf{1 6 b}$ and obtained as white solid. Yield: 95\%. ${ }^{1} \mathrm{H}$ NMR $\left(300 \mathrm{MHz}, \mathrm{CDCl}_{3}\right) \delta_{\mathrm{H}} 8.18(1 \mathrm{H}, \mathrm{s}, \mathrm{CH}), 7.55\left(2 \mathrm{H}, \mathrm{d},{ }^{3}{ }_{\mathrm{HH}} 9.7, \mathrm{CH}\right.$ aromatic), 7.25-7.45 $(5 \mathrm{H}, \mathrm{m}, \mathrm{CH}$ aromatic), $7.00\left(2 \mathrm{H}, \mathrm{d},{ }^{3} \mathrm{~J}_{\mathrm{HH}} 9.7, \mathrm{CH}\right.$ aromatic), $5.12\left(2 \mathrm{H}, \mathrm{s}, \mathrm{CH}_{2}\right) \mathrm{ppm}$.

4-Chlorobenzaldehyde oxime (17c) was synthesized starting from $16 \mathrm{c}$ and obtained as white solid. Yield: $95 \%$. ${ }^{1} \mathrm{H}$ NMR $\left(300 \mathrm{MHz}, \mathrm{CDCl}_{3}\right) \delta_{\mathrm{H}} 8.04(1 \mathrm{H}, \mathrm{s}, \mathrm{CH}), 7.43\left(2 \mathrm{H}, \mathrm{d},{ }^{3} J_{\mathrm{HH}} 8.5, \mathrm{CH}\right.$ aromatic), $7.29\left(2 \mathrm{H}, \mathrm{d},{ }^{3} \mathrm{~J}_{\mathrm{HH}} 8.5, \mathrm{CH}\right.$ aromatic), 6.67 (broad s, $1 \mathrm{H}, \mathrm{NOH}$ exchanged with $\mathrm{D}_{2} \mathrm{O}$ ) ppm.

General procedure for the synthesis of benzoyl chloride oximes (18a-c). The suitable benzaldehyde oxime $(17 \mathrm{a}-\mathrm{c}, 15 \mathrm{mmol})$ was dissolved in $\mathrm{N}, \mathrm{N}$-dimethylformamide $(6 \mathrm{~mL})$ and a first portion of $\mathrm{N}$-chlorosuccinimide (NCS, $3 \mathrm{mmol}$ ) was added. The reaction mixture was cooled at $0^{\circ} \mathrm{C}$ and a second amount of NCS $(12 \mathrm{mmol})$ was introduced. The solution was stirred for $12 \mathrm{~h}$ at $\mathrm{rt}$. After addition of water $(10 \mathrm{~mL})$ to the reaction mixture, the solvent was evaporated under vacuum. The aqueous solution was extracted by EtOAc $(3 \times 10 \mathrm{~mL})$. The organic phases were collected, dried over $\mathrm{Na}_{2} \mathrm{SO}_{4}$ and evaporated under vacuum to give the correspondent crude hydroxylimino derivative (18a-c), that was directly used without further purification in the next reaction.

tert-Butyl \{4-[chloro(hydroxyimino)methyl]benzyl\}carbamate (18a) was synthesized starting from 17a. Pale oil. Quantitative yield. ${ }^{1} \mathrm{H}$ NMR $\left(300 \mathrm{MHz} \mathrm{CDCl}_{3}\right) \delta_{\mathrm{H}} 8.55\left(1 \mathrm{H}\right.$, broad s, NOH exchanged with $\left.\mathrm{D}_{2} \mathrm{O}\right), 7.75(2 \mathrm{H}, \mathrm{d}$, ${ }^{3} \mathrm{~J}_{\mathrm{HH}} 7.8 \mathrm{~Hz}, \mathrm{CH}$ aromatic), $7.31\left(2 \mathrm{H}, \mathrm{d},{ }^{3} \mathrm{~J}_{\mathrm{HH}} 7.8 \mathrm{~Hz}, \mathrm{CH}\right.$ aromatic), $4.93\left(1 \mathrm{H}\right.$, broad s, $\mathrm{NH}$, exchanged with $\left.\mathrm{D}_{2} \mathrm{O}\right)$, $4.35\left(2 \mathrm{H}, \mathrm{d},{ }^{2} \mathrm{~J}_{\mathrm{HH}} 6.1 \mathrm{~Hz}, \mathrm{CH}_{2}\right), 1.47\left(9 \mathrm{H}, \mathrm{s}, \mathrm{C}\left(\mathrm{CH}_{3}\right)_{3}\right) \mathrm{ppm}$.

4-Benzyloxybenzoyl chloride oxime (18b) was synthesized starting from $\mathbf{1 7 b}$ and obtained as white solid. Quantitative yield. ${ }^{1} \mathrm{H}$ NMR $\left(300 \mathrm{MHz}, \mathrm{CDCl}_{3}\right) \delta_{\mathrm{H}} 8.22\left(1 \mathrm{H}\right.$, broad s, NOH exchanged with $\left.\mathrm{D}_{2} \mathrm{O}\right), 7.78\left(2 \mathrm{H}, \mathrm{d},{ }^{3} \mathrm{~J}_{\mathrm{HH}}\right.$ 8.7 Hz, CH aromatic), 7.46-7.29 (5H, m, CH aromatic), $6.98\left(2 \mathrm{H}, \mathrm{d},{ }^{3}{ }_{\mathrm{HH}} 8.7 \mathrm{~Hz}, \mathrm{CH}\right.$ aromatic), $5.10\left(2 \mathrm{H}, \mathrm{s}, \mathrm{CH}_{2}\right)$ ppm.

4-Chlorobenzoyl chloride oxime (18c) was synthesized starting from 17c and obtained as pale oil. Yield $92 \%$. ${ }^{1} \mathrm{H}$ NMR $\left(300 \mathrm{MHz}, \mathrm{CDCl}_{3}\right) \delta_{\mathrm{H}} 9.21\left(1 \mathrm{H}\right.$, broad s, NOH exchanged with $\left.\mathrm{D}_{2} \mathrm{O}\right), 7.74\left(2 \mathrm{H}, \mathrm{d},{ }^{3} J_{\mathrm{HH}} 8.7 \mathrm{~Hz}, \mathrm{CH}\right.$ aromatic), $7.32\left(2 \mathrm{H}, \mathrm{d},{ }^{3} \mathrm{~J}_{\mathrm{HH}} 8.7 \mathrm{~Hz}, \mathrm{CH}\right.$ aromatic) ppm.

General procedure for the synthesis of 2-(hydroxyimino)acetonitriles (19a-c). The required chloride oxime (18a-c, $4.8 \mathrm{mmol})$ was dissolved in $\mathrm{Et}_{2} \mathrm{O}(20 \mathrm{~mL})$ and cooled to $0^{\circ} \mathrm{C}$. A solution of $\mathrm{KCN}(9.6 \mathrm{mmol})$ dissolved in water $(10 \mathrm{~mL})$ was added and the reaction mixture was stirred at $\mathrm{rt}$ for $5 \mathrm{~h}$. Subsequently the organic layer was separated and the aqueous phase was extracted by EtOAc $(3 \times 10 \mathrm{~mL})$. The organic solvent was dried over $\mathrm{Na}_{2} \mathrm{SO}_{4}$ and evaporated under reduced pressure to give the crude 2-(hydroxyimino)acetonitriles (19a-c).

tert-Butyl \{4-[cyano(hydroxyimino)methyl]benzyl)\}carbamate (19a) was synthesized starting from 18a and it was directly used without further purification in the next reaction. Yellow solid. Yield 98\%. ${ }^{1} \mathrm{H} \mathrm{NMR}(300 \mathrm{MHz}$, $\left.\mathrm{CDCl}_{3}\right) \delta_{\mathrm{H}} 10.15\left(1 \mathrm{H}\right.$, broad s, NOH exchanged with $\left.\mathrm{D}_{2} \mathrm{O}\right), 7.70-7.28(4 \mathrm{H}, \mathrm{m}, \mathrm{CH}$ aromatic), $5.04(1 \mathrm{H}, \mathrm{bs}, \mathrm{NH}$ exchanged with $\left.\mathrm{D}_{2} \mathrm{O}\right), 4.37\left(2 \mathrm{H}, \mathrm{s}, \mathrm{CH}_{2}\right), 1.47\left(9 \mathrm{H}, \mathrm{s}, \mathrm{C}\left(\mathrm{CH}_{3}\right)_{3}\right) \mathrm{ppm}$.

4-Benzyloxyphenyl-2-(hydroxyimino)acetonitrile (19b) was synthesized starting from 18b. The crude was purified by flash chromatography (eluting with cyclohexane/EtOAc 9:1) and a white solid was obtained. Yield: 61\%. ${ }^{1} \mathrm{H}-\mathrm{NMR}\left(300 \mathrm{MHz}\right.$, acetone- $\left.d_{6}\right) \delta_{\mathrm{H}} 12.36\left(1 \mathrm{H}\right.$, broad s, NOH exchanged with $\left.\mathrm{D}_{2} \mathrm{O}\right), 7.73\left(2 \mathrm{H}, \mathrm{d}^{3}{ }^{3} \mathrm{HH} 8.7 \mathrm{~Hz}\right.$, $\mathrm{CH}$ aromatic), 7.27-7.55 (5H, m, CH aromatic), $7.15\left(2 \mathrm{H}, \mathrm{d},{ }^{3} \mathrm{~J}_{\mathrm{HH}} 8.7 \mathrm{~Hz}, \mathrm{CH}\right.$ aromatic), $5.20\left(2 \mathrm{H}, \mathrm{s}, \mathrm{CH}_{2}\right) \mathrm{ppm}$. 
4-Chlorophenyl-2-(hydroxyimino)acetonitrile (19c) was synthesized starting from 18c. The crude was purified by flash chromatography (eluting with cyclohexane/EtOAc 9:1) and a yellow solid was obtained. Yield: $87 \%$. ${ }^{1} \mathrm{H}$ NMR $\left(300 \mathrm{MHz}, \mathrm{CDCl}_{3}\right) \delta_{\mathrm{H}} 9.59\left(1 \mathrm{H}\right.$, broad s, $\mathrm{NOH}$ exchanged with $\left.\mathrm{D}_{2} \mathrm{O}\right), 7.78\left(2 \mathrm{H}, \mathrm{d},{ }^{3} \mathrm{~J}_{\mathrm{HH}} 9 \mathrm{~Hz}, \mathrm{CH}\right.$ aromatic), $7.42\left(2 \mathrm{H}, \mathrm{d},{ }^{3} \mathrm{~J}_{\mathrm{HH}} 9 \mathrm{~Hz}, \mathrm{CH}\right.$ aromatic) ppm.

General procedure for the synthesis of acetamidines (20a-c). To a solution of the appropriate intermediate (19a-c, $4.7 \mathrm{mmol})$ in $\mathrm{MeOH}(13 \mathrm{~mL}), \mathrm{NH}_{2} \mathrm{OH} \cdot \mathrm{HCl}(7.1 \mathrm{mmol})$ and $\mathrm{NaHCO}_{3}(7.1 \mathrm{mmol})$ in water $(6 \mathrm{~mL}) \mathrm{were}$ added. The mixture was refluxed under stirring for $12 \mathrm{~h}$ and the organic solvent was removed under vacuum. The aqueous phase was extracted by EtOAc $(3 \times 10 \mathrm{~mL})$ and the collected organic layers were dried over $\mathrm{Na}_{2} \mathrm{SO}_{4}$ and evaporated under reduced pressure to give the crude acetamidine intermediates (20a-c), directly used without further purification in the next reaction.

tert-Butyl \{4-[2-amino-1,2-bis(hydroxyimino)ethyl]benzyl\}carbamate (20a) was synthesized starting from 19a. White solid. Yield 91\%. ${ }^{1} \mathrm{H}$ NMR (300 MHz, CD $\left.{ }_{3} \mathrm{OD}\right) \delta_{\mathrm{H}} 7.62\left(2 \mathrm{H}, \mathrm{d},{ }^{3} \mathrm{~J}_{\mathrm{HH}} 8.4 \mathrm{~Hz}, \mathrm{CH}\right.$ aromatic), $7.26(2 \mathrm{H}, \mathrm{d}$, ${ }^{3} \mathrm{~J}_{\mathrm{HH}} 8.4 \mathrm{~Hz}, \mathrm{CH}$ aromatic), $4.23\left(2 \mathrm{H}, \mathrm{s}, \mathrm{CH}_{2}\right), 1.45\left(9 \mathrm{H}, \mathrm{s}, \mathrm{C}\left(\mathrm{CH}_{3}\right)_{3}\right) \mathrm{ppm}$.

2-[4-(Benzyloxy)phenyl]-N'-hydroxy-2-(hydroxyimino)acetimidamide (20b) was synthesized starting from 19b and obtained as light yellow solid. Yield: $99 \% .{ }^{1} \mathrm{H}$ NMR $\left(300 \mathrm{MHz}\right.$, acetone- $\left.\mathrm{d}_{6}\right) \delta_{\mathrm{H}} 10.80(1 \mathrm{H}$, broad s, NOH exchanged with $\left.\mathrm{D}_{2} \mathrm{O}\right), 8.94\left(1 \mathrm{H}\right.$, broad $\mathrm{s}$, $\mathrm{NOH}$ exchanged with $\left.\mathrm{D}_{2} \mathrm{O}\right), 7.60\left(2 \mathrm{H}, \mathrm{d},{ }^{3} \mathrm{~J}_{\mathrm{HH}} 9.0 \mathrm{~Hz}, \mathrm{CH}\right.$ aromatic), 7.45-7.52 (2H, m, CH aromatic), 7.24-7.45 (3H, m, CH aromatic), $7.00\left(2 \mathrm{H}, \mathrm{d}^{3}{ }^{3} \mathrm{JHH}_{\mathrm{HH}} 9.0 \mathrm{~Hz}, \mathrm{CH}\right.$ aromatic), 5.45 $\left(2 \mathrm{H}\right.$, broad $\mathrm{s}, \mathrm{NH}_{2}$ exchanged with $\left.\mathrm{D}_{2} \mathrm{O}\right), 5.16\left(2 \mathrm{H}, \mathrm{s}, \mathrm{CH}_{2}\right) \mathrm{ppm}$.

2-(4-Chlorophenyl)-N'-hydroxy-2-(hydroxyimino)acetimidamide (20c) was synthesized starting from 19c and obtained as white solid. Yield: $95 \% .{ }^{1} \mathrm{H}$ NMR $\left(300 \mathrm{MHz}, \mathrm{CD}_{3} \mathrm{OD}\right) \delta_{\mathrm{H}} 7.64\left(2 \mathrm{H}, \mathrm{d},{ }^{3} \mathrm{~J}_{\mathrm{HH}} 8.5 \mathrm{~Hz}, \mathrm{CH}\right.$ aromatic), 7.34 $\left(2 \mathrm{H}, \mathrm{d},{ }^{3} \mathrm{~J}_{\mathrm{HH}} 8.5 \mathrm{~Hz}, \mathrm{CH}\right.$ aromatic) ppm.

General procedure for the synthesis of 4-phenyl-1,2,5-oxadiazol-3-amines (21a-c). Each acetamidine derivative (20a-c, $4.3 \mathrm{mmol})$ was dissolved in $2 \mathrm{~N} \mathrm{NaOH}(43 \mathrm{~mL})$ and the solution refluxed under stirring for 12 h. After cooling, the volume of the mixture was reduced to approximately $10 \mathrm{~mL}$ and the so formed precipitate was collected by filtration and dried under vacuum. The crude product was then purified as indicated for each compound.

tert-Butyl [4-(4-amino-1,2,5-oxadiazol-3-yl)benzyl]carbamate (21a). The solid obtained from the $\mathrm{NaOH}$ treatment was then dissolved in $\mathrm{CH}_{2} \mathrm{Cl}_{2}$, cooled in an ice bath, and triethylamine $(0.8 \mathrm{mmol})$ followed by tertbutyloxycarbonyl anhydride $(0.8 \mathrm{mmol})$ were added. The mixture was left 4 hours at $\mathrm{rt}$, after that time the solvent was removed under vacuum, the residue dissolved in $\mathrm{CH}_{2} \mathrm{Cl}_{2}$ and washed with sat. $\mathrm{NaHCO}_{3}$, water and brine. The organic solvent was dried over $\mathrm{Na}_{2} \mathrm{SO}_{4}$ and evaporated under reduced pressure to give crude oxadiazole (21a) which was purified by preparative HPLC (column: SunFire Prep C18 $19 \times 150$ mm, gradient: $\mathrm{H}_{2} \mathrm{O}+$ TFA 0.1\% - MeOH + TFA 0.1\%). Solid. Yield: $38 \% .{ }^{1} \mathrm{H}$ NMR $\left(300 \mathrm{MHz}, \mathrm{CD}_{3} \mathrm{OD}\right) \delta_{\mathrm{H}} 7.98\left(2 \mathrm{H}, \mathrm{d},{ }^{3} \mathrm{~J}_{\mathrm{HH}} 8.2 \mathrm{~Hz}\right.$, $\mathrm{CH}$ aromatic), $7.38\left(2 \mathrm{H}, \mathrm{d}^{3}{ }^{3} \mathrm{HH}_{\mathrm{HH}} 8.2 \mathrm{CH}\right.$ aromatic), $4.30\left(2 \mathrm{H}, \mathrm{s}, \mathrm{CH}_{2}\right), 1.47\left(9 \mathrm{H}, \mathrm{s}, \mathrm{C}\left(\mathrm{CH}_{3}\right)_{3}\right) \mathrm{ppm}$.

4-[4-(Benzyloxy)phenyl]-1,2,5-oxadiazol-3-amine (21b) was synthesized starting from 20b and the crude was purified by flash chromatography (eluting with cyclohexane/EtOAc 7:3) to give a white solid. Yield: $80 \% .{ }^{1} \mathrm{H}$ NMR $\left(300 \mathrm{MHz}, \mathrm{CDCl}_{3}\right) \delta_{\mathrm{H}} 7.66\left(2 \mathrm{H}, \mathrm{d},{ }^{3} \mathrm{~J}_{\mathrm{HH}} 8.8 \mathrm{~Hz}, \mathrm{CH}\right.$ aromatic), 7.29-7.49 (5H, m, CH aromatic), 7.11 (2H, d, ${ }^{3} \mathrm{~J}_{\mathrm{HH}} 8.8 \mathrm{~Hz}, \mathrm{CH}$ aromatic), $5.14\left(2 \mathrm{H}, \mathrm{s}, \mathrm{CH}_{2}\right), 4.19\left(2 \mathrm{H}\right.$, broad $\mathrm{s}, \mathrm{NH}_{2}$ exchanged with $\left.\mathrm{D}_{2} \mathrm{O}\right) \mathrm{ppm} .{ }^{13} \mathrm{C} \mathrm{NMR}(75$ $\left.\mathrm{MHz}_{2} \mathrm{CDCl}_{3}\right) \delta_{\mathrm{C}} 160.67,154.21,146.79,136.49,129.31,128.95,128.47,127.69,118.24,116.01,70.37$ ppm.

4-(4-Chlorophenyl)-1,2,5-oxadiazol-3-amine (21c) was synthesized starting from 20c and the crude was purified by flash chromatography (eluting with cyclohexane/EtOAc 8:2) to afford a white solid. Yield: $38 \% .{ }^{1} \mathrm{H}$ NMR $\left(300 \mathrm{MHz}, \mathrm{CDCl}_{3}\right) \delta_{\mathrm{H}} 7.69\left(2 \mathrm{H}, \mathrm{d},{ }^{3} J_{\mathrm{HH}} 8.2 \mathrm{~Hz}, \mathrm{CH}\right.$ aromatic), $7.52\left(2 \mathrm{H}, \mathrm{d},{ }^{3} \mathrm{~J}_{\mathrm{HH}} 8.0 \mathrm{~Hz}, \mathrm{CH}\right.$ aromatic), 4.21 $\left(2 \mathrm{H}\right.$, broad $\mathrm{s}, \mathrm{NH}_{2}$ exchanged with $\left.\mathrm{D}_{2} \mathrm{O}\right) \mathrm{ppm} .{ }^{13} \mathrm{C}$ NMR $\left(75 \mathrm{MHz}\right.$, acetone- $\left.d_{6}\right): \delta_{\mathrm{C}} 155.10,146.20,135.77$, $129.44,129.31,124.95 \mathrm{ppm}$. 
General procedure for the synthesis of $\mathbf{N}$-(4-phenyl-1,2,5-oxadiazol-3-yl)benzamides $(22,24,26)$. In a twonecked flame dried flask, $60 \% \mathrm{NaH}$ mineral oil $(0.3 \mathrm{mmol}$ ) was suspended in dry $\mathrm{N}, \mathrm{N}$-dimethylformamide (3 $\mathrm{mL}$ ) under nitrogen. The suspension was cooled in an ice bath and the appropriate key intermediate (21a-c, $0.25 \mathrm{mmol}$ ) was added. The mixture was stirred for $20 \mathrm{~min}$ at $0^{\circ} \mathrm{C}$. Then, the suitable commercially available acyl chloride $(0.3 \mathrm{mmol})$ was added dropwise and the mixture was stirred at $60^{\circ} \mathrm{C}$ for $12 \mathrm{~h}$. The reaction was quenched with water $(3 \mathrm{~mL})$ and $N, N$-dimethylformamide was removed under vacuum. The residue was extracted with EtOAc $(3 \times 2 \mathrm{~mL})$; the organic layer was dried over $\mathrm{Na}_{2} \mathrm{SO}_{4}$ and evaporated in vacuo. The crude product was purified by column chromatography to obtain the desired adduct.

tert-Butyl (4-\{4-[4-(trifluoromethyl)benzamido]-1,2,5-oxadiazol-3-yl\}benzyl)carbamate (22) was synthesized starting from 21a and 4-(trifluoromethyl)benzoyl chloride. After purification by preparative HPLC (column: SunFire Prep C18 19 × 150 mm, gradient: $\mathrm{H}_{2} \mathrm{O}+$ TFA 0.1\% - MeOH + TFA 0.1\%) amide 22 was obtained as a white solid. Yield: $33 \% .{ }^{1} \mathrm{H}$ NMR $\left(300 \mathrm{MHz} \mathrm{CDCl}_{3}\right) \delta_{\mathrm{H}} 8.66\left(1 \mathrm{H}\right.$, broad s, NH exchanged with $\left.\mathrm{D}_{2} \mathrm{O}\right), 7.99(2 \mathrm{H}, \mathrm{d}$, ${ }^{3} \mathrm{~J}_{\mathrm{HH}} 8.1 \mathrm{~Hz}, \mathrm{CH}$ aromatic), $7.77\left(2 \mathrm{H}, \mathrm{d},{ }^{3} \mathrm{~J}_{\mathrm{HH}} 8.2 \mathrm{~Hz}, \mathrm{CH}\right.$ aromatic), $7.64\left(2 \mathrm{H}, \mathrm{d},{ }^{3} \mathrm{~J}_{\mathrm{HH}} 8.1 \mathrm{~Hz}, \mathrm{CH}\right.$ aromatic $), 7.39(2 \mathrm{H}$, $\mathrm{d},{ }^{3} \mathrm{~J}_{\mathrm{HH}} 8.0 \mathrm{~Hz}, \mathrm{CH}$ aromatic), $4.99\left(1 \mathrm{H}, \mathrm{t},{ }^{3} \mathrm{~J}_{\mathrm{HH}} 6.1 \mathrm{~Hz}, \mathrm{NH}\right.$ exchanged with $\left.\mathrm{D}_{2} \mathrm{O}\right), 4.33\left(2 \mathrm{H}, \mathrm{d},{ }^{2} \mathrm{~J}_{\mathrm{HH}} 6.2 \mathrm{~Hz}, \mathrm{CH}_{2}\right), 1.44$ $\left(9 \mathrm{H}, \mathrm{s}, \mathrm{C}\left(\mathrm{CH}_{3}\right)_{3}\right) \mathrm{ppm}$.

4-Trifluoromethyl-N-[4-(4-benzyloxyphenyl)-1,2,5-oxadiazol-3-yl]benzamide (24) was synthesized starting from 21b and 4-(trifluoromethyl)benzoyl chloride. The crude was purified by flash chromatography (eluting with cyclohexane/EtOAc 7:3) affording a white-gray solid. Yield: $30 \% .{ }^{1} \mathrm{H} N M R\left(300 \mathrm{MHz} \mathrm{CDCl}_{3}\right) \delta_{\mathrm{H}} 8.11(1 \mathrm{H}$, broad s, NH exchanged with $\left.\mathrm{D}_{2} \mathrm{O}\right), 7.99\left(2 \mathrm{H}, \mathrm{d},{ }^{3} \mathrm{~J}_{\mathrm{HH}} 8.7 \mathrm{~Hz}, \mathrm{CH}\right.$ aromatic), $7.79\left(2 \mathrm{H}, \mathrm{d},{ }^{3} \mathrm{~J}_{\mathrm{HH}} 8.7 \mathrm{~Hz}, \mathrm{CH}\right.$ aromatic), $7.64\left(2 \mathrm{H}, \mathrm{d},{ }^{3} \mathrm{~J}_{\mathrm{HH}} 9.0 \mathrm{~Hz}, \mathrm{CH}\right.$ aromatic), 7.35-7.44 (5H, m, CH aromatic), $7.09\left(2 \mathrm{H}, \mathrm{d},{ }^{3} \mathrm{~J}_{\mathrm{HH}} 9.0 \mathrm{~Hz}, \mathrm{CH}\right.$ aromatic), $5.12\left(2 \mathrm{H}, \mathrm{s}, \mathrm{CH}_{2}\right) \mathrm{ppm} .{ }^{13} \mathrm{C} \mathrm{NMR}\left(75 \mathrm{MHz} \mathrm{CDCl}_{3}\right): \delta_{\mathrm{C}} 136.37129 .36,129.00,128.53,128.32,127.73,126.49$, 116.10, 70.37 ppm.

4-Nitro- $\mathbf{N}$-[4-(4-chlorophenyl)-1,2,5-oxadiazol-3-yl]benzamide (26) was synthesized starting from 21c and 4nitrobenzoyl chloride. The crude was purified by flash chromatography (eluting from dichloromethane / cyclohexane (98:2) to dichloromethane / EtOAc (7:3)) giving a yellow solid. Yield: 46\%. mp 229.9-230.2 ${ }^{\circ} \mathrm{C} .{ }^{1} \mathrm{H}$ NMR $\left(300 \mathrm{MHz}\right.$, acetone- $\left.\mathrm{d}_{6}\right): \delta_{\mathrm{H}} 10.70\left(1 \mathrm{H}\right.$, broad s, NH exchanged with $\left.\mathrm{D}_{2} \mathrm{O}\right), 8.41\left(2 \mathrm{H}, \mathrm{d},{ }^{3} J_{\mathrm{HH}} 9 \mathrm{~Hz}, \mathrm{CH}\right.$ aromatic), $8.29\left(2 \mathrm{H}, \mathrm{d},{ }^{3} \mathrm{~J}_{\mathrm{HH}} 9 \mathrm{~Hz}, \mathrm{CH}\right.$ aromatic), $7.87\left(2 \mathrm{H}, \mathrm{d},{ }^{3} J_{\mathrm{HH}} 9 \mathrm{~Hz}, \mathrm{CH}\right.$ aromatic), $7.56\left(2 \mathrm{H}, \mathrm{d},{ }^{3} \mathrm{~J}_{\mathrm{HH}} 9 \mathrm{~Hz}, \mathrm{CH}\right.$ aromatic) ppm. ${ }^{13} \mathrm{C}$ NMR $\left(75 \mathrm{MHz}\right.$, acetone- $\left.d_{6}\right): \delta_{\mathrm{C}} 165.00,150.98,150.69,149.92,138.19,136.50,129.79$, $129.55,129.48,124.87,123.99 \mathrm{ppm}$.

$\mathbf{N}$-[4-(4-Aminomethylphenyl)-1,2,5-oxadiazol-3-yl]-4-(trifluoromethyl)benzamide hydrochloride Compound $22(0.22 \mathrm{mmol})$ was dissolved with $4 \mathrm{M} \mathrm{HCl}$ in 1,4-dioxane $(1 \mathrm{~mL})$ at $0{ }^{\circ} \mathrm{C}$. The reaction was stirred at $r$ for 30 minutes. After completion of the reaction, monitored by $\mathrm{TLC}\left(\mathrm{CH}_{2} \mathrm{Cl}_{2} / \mathrm{MeOH} 85: 15\right)$, the solvent was stripped off and the formed precipitate was washed with cold $\mathrm{Et}_{2} \mathrm{O}$ and dried to afford hydrochloride acid salt of compound 23.

4-[4-(4-Hydroxyphenyl)-1,2,5-oxadiazol-3-yl]-4-trifluoromethylbenzamide (25). A solution of 24 (0.54 mmol) and catalytic amount of $10 \%$ palladium on carbon $(10 \% \mathrm{p} / \mathrm{p})$ in EtOAc $(9 \mathrm{~mL})$ and $\mathrm{MeOH}(1 \mathrm{~mL}) \mathrm{was}$ hydrogenated at rt for 24 hours. The resulting mixture was filtered and extracted with $\mathrm{Et}_{2} \mathrm{O}(3 \times 10 \mathrm{~mL})$. The organic layer was dried over $\mathrm{Na}_{2} \mathrm{SO}_{4}$, filtered and evaporated in vacuum. Under reduced pressure the crude oil was purified by flash chromatography eluting with cyclohexane/EtOAc (7:3) to afford the final compound as white foam. Yield: 91.5\%. ${ }^{1} \mathrm{H}-\mathrm{NMR}\left(300 \mathrm{MHz}\right.$, acetone- $\left.d_{6}\right): \delta_{\mathrm{H}} 10.38\left(1 \mathrm{H}\right.$, broad s, $\mathrm{NH}$ exchanged with $\left.\mathrm{D}_{2} \mathrm{O}\right)$, $8.92\left(1 \mathrm{H}\right.$, broad s, OH exchanged with $\left.\mathrm{D}_{2} \mathrm{O}\right), 8.26\left(2 \mathrm{H}, \mathrm{d},{ }^{3} \mathrm{~J}_{\mathrm{HH}} 9 \mathrm{~Hz}, \mathrm{CH}\right.$ aromatic), $7.93\left(2 \mathrm{H}, \mathrm{d},{ }^{3} \mathrm{~J}_{\mathrm{HH}} 9 \mathrm{~Hz}, \mathrm{CH}\right.$ aromatic), $7.71\left(2 \mathrm{H}, \mathrm{d},{ }^{3} \mathrm{~J}_{\mathrm{HH}} 9 \mathrm{~Hz}, \mathrm{CH}\right.$ aromatic), $6.95\left(2 \mathrm{H}, \mathrm{d},{ }^{3} \mathrm{~J}_{\mathrm{HH}} 9 \mathrm{~Hz}, \mathrm{CH}\right.$ aromatic) ppm. ${ }^{13} \mathrm{C} \mathrm{NMR}(75 \mathrm{MHz}$, DMSO- $\left.d_{6}\right): \delta_{C} 164.7,158.5,147.3,145.2,137.5,134.4,128.9,127.8,125.6,125.2,124.1,116.4$ ppm. 
4-Amino-N-[4-(4-chlorophenyl)-1,2,5-oxadiazol-3-yl]benzamide (27). To a solution of 26 (0.062 mmol) in EtOAc $(4 \mathrm{~mL}), \operatorname{tin}(\mathrm{II})$ chloride $(0.310 \mathrm{mmol})$ was added and the mixture was refluxed for $4 \mathrm{~h}$. The reaction was then quenched by addition of a saturated aqueous solution of $\mathrm{NaHCO}_{3}$ until $\mathrm{pH}=7-8$ to allow the precipitation of tin salts. The resulting mixture was filtered and washed several times with EtOAc. The aqueous phase was extracted with EtOAc $(3 \times 10 \mathrm{~mL})$. The organic layer was dried over $\mathrm{Na}_{2} \mathrm{SO}_{4}$, filtered and evaporated in vacuo. The residue was purified on silica gel column chromatography (eluent: cyclohexane/EtOAc 6:4) to give 27 as yellow solid. Yield $70 \%$ mp $153.5-154{ }^{\circ} \mathrm{C} .{ }^{1} \mathrm{H}-\mathrm{NMR}\left(300 \mathrm{MHz}\right.$, acetone- $\left.d_{6}\right): \delta_{\mathrm{H}} 9.82(1 \mathrm{H}$, broad s, $\mathrm{NH}$ exchanged with $\left.\mathrm{D}_{2} \mathrm{O}\right), 7.64-7.73\left(4 \mathrm{H}, \mathrm{m}, \mathrm{CH}\right.$ aromatic), $7.40\left(2 \mathrm{H}, \mathrm{d},{ }^{3} \mathrm{~J}_{\mathrm{HH}} 8.7 \mathrm{~Hz}, \mathrm{CH}\right.$ aromatic), $6.60\left(2 \mathrm{H}, \mathrm{d},{ }^{3} \mathrm{~J}_{\mathrm{HH}} 8.4 \mathrm{~Hz}, \mathrm{CH}\right.$ aromatic), $5.35\left(2 \mathrm{H}\right.$, broad s, $\mathrm{NH}_{2}$ exchanged with $\left.\mathrm{D}_{2} \mathrm{O}\right) \mathrm{ppm} .{ }^{13} \mathrm{C} \mathrm{NMR}\left(75 \mathrm{MHz}\right.$, acetone- $\left.d_{6}\right): \delta_{\mathrm{C}} 166.09,153.41$, $151.15,150.88,136.17,130.26,129.36,129.30,125.46,119.84,113.35$ ppm.

Cell culture. The colorectal HCT116 cell lines were cultured in McCoy's media supplemented with penicillin $(10,000 \mathrm{U} / \mathrm{mL})$, streptomycin $(10 \mathrm{mg} / \mathrm{mL})$, nonessential amino acid and $10 \%$ Fetal Calf Serum (FCS). Cells were incubated with newly synthesized compounds dissolved in DMSO. The same volume of solvent was added to control conditions and did not exceed $0.5 \% \mathrm{v} / \mathrm{v}$.

MTT-assay. The determination of the conversion of MTT (MTT = 3-(4,5-dimethyl-2-thiazolyl)-2,5-diphenyl-2Htetrazolium bromide) to formazan was determined as previously described. ${ }^{25,26}$

AlphaScreen-based Assay. The AlphaScreen-based assay was performed according to literature data. ${ }^{24}$

\section{Acknowledgements}

This study was supported by funds from PRIN 2010-2011. Authors also thank Fondazione Confalonieri (Fellowship 2015) for the financial support.

\section{References}

1. Fisher, G. Adv. Heterocycl. Chem. 2013, 109, 1-90.

http://dx.doi.org/10.1016/B978-0-12-407777-5.00001-4

2. Roth, P. J.; Theato, P. Polymer Preprints 2010, 51(2), 746-747.

3. Reddy, B. S.; Kawamori, T.; Lubet, R.; Steele, V.; Kelloff, G.; Rao, C. V. Carcinogenesis 1999, 20, 16451648.

http://dx.doi.org/10.1093/carcin/20.8.1645

4. Bass, S.E.; Sienkiewicz, P.; Macdonald, C.J.; Cheng, R.Y.; Sparatore, A.; Del Soldato, P.; Roberts, D.D.; Moody, T.W.; Wink, D.A.; Yeh, G.C. Clin. Cancer Res. 2009, 15, 1964-1972.

http://dx.doi.org/10.1158/1078-0432.CCR-08-1870

5. Perrino, E.; Cappelletti, G.; Tazzari, V.; Giavini, E.; Del Soldato, P.; Sparatore, A. Bioorg. Med. Chem. Lett. 2008, 18, 1893-1897.

http://dx.doi.org/10.1016/j.bmcl.2008.02.007

6. Wedel, S. A.; Sparatore, A.; Soldato, P. D.; Al-Batran, S. E.; Atmaca, A.; Juengel, E.; Hudak, L.; Jonas, D.; Blaheta, R. A. J. Cell. Mol. Med. 2008, 12, 2457-2466.

http://dx.doi.org/10.1111/j.1582-4934.2008.00271.x 
7. Tesei, A.; Brigliadori, G.; Carloni, S.; Fabbri, F.; Ulivi, P.; Arienti, C.; Sparatore, A.; Del Soldato, P.; Pasini, A.; Amadori, D.; Silvestrini, R.; Zoli. W. J. Cell. Physiol. 2012, 227, 3389-3396.

http://dx.doi.org/10.1002/jcp.24039

8. Carey, K. A.; Kensler, T. W.; Fishbein, J. C. Chem. Res. Toxicol. 2001, 14, 939-945. http://dx.doi.org/10.1021/tx0100340

9. Pan, J.; Carroll, K. S. ACS Chem. Biol. 2013, 8, 1110-1116.

http://dx.doi.org/10.1021/cb4001052

10. Switzer, C. H.; Cheng, R. Y.; Ridnour, L. A.; Murray, M. C.; Tazzari, V.; Sparatore, A.; Del Soldato, P.; Hines, H. B.; Glynn, S. A.; Ambs, S.; Wink, D. A. Cancer Res. 2012, 72, 2394-2404.

http://dx.doi.org/10.1158/0008-5472.CAN-11-3115

11. Masciocchi, D.; Gelain, A.; Villa, S.; Meneghetti, F.; Barlocco D. Future Med. Chem. 2011, 5, 567-597. http://dx.doi.org/10.4155/fmc.11.22

12. Schust, J.; Sperl, B.; Hollis, A.; Mayer, T.U.; Berg, T. Chem. Biol. 2006, 13, 1235-1242.

http://dx.doi.org/10.1016/j.chembiol.2006.09.018

13. Lai, P.S.; Rosa, D.A.; Magdy Ali, A.; Gómez-Biagi, R. F.; Ball D. P.; Shouksmith, A. E.; Gunning, P. T. Expert Opin. Ther. Pat. 2015, 25, 1397-1421.

http://dx.doi.org/10.1517/13543776.2015.1086749

14. Shin, D.-S.; Masciocchi, D.; Gelain, A.; Villa, S.; Barlocco, D.; Meneghetti, F.; Pedretti, A.; Han, Y-M.; Han, D. C.; Kwon, B.M.; Legnani, L.; Toma, L. MedChemComm 2010, 1, 156-164.

http://dx.doi.org/10.1039/c0md00057d

15. Villa, S.; Masciocchi, D.; Gelain, A.; Meneghetti, F., Chem. Biodiv. 2012, 9, 1240-1253.

http://dx.doi.org/10.1002/cbdv.201100339

16. Masciocchi, D.; Villa, S.; Meneghetti, F.; Pedretti, A.; Barlocco, D.; Legnani, L.; Toma, L.; Kwon, B. M.; Nakano, S.; Asai, A.; Gelain, A. MedChemComm 2012, 3, 592-599.

http://dx.doi.org/10.1039/c2md20018j

17. Meneghetti, F.; Villa, S.; Masciocchi, D.; Barlocco, D.; Toma, L.; Han, D. C.; Kwon, B. M.; Ogo, N.; Asai, A.; Legnani, L.; Gelain, A. Eur. J. Org. Chem. 2015, 22, 4907-4912.

http://dx.doi.org/10.1002/ejoc.201500599

18. Lee, M.; Tazzari, V.; Giustarini, D.; Rossi, R.; Sparatore, A.; Del Soldato, P.; McGeer, E.; McGeer, P.L. J. Biol. Chem. 2010, 285, 17318-17328.

http://dx.doi.org/10.1074/jbc.M110.115261

19. Sparatore, A.; Del Soldato, P.; Santus G. PCT Int. Appl. WO 2009065926, 2009.

20. Rai, G.; Thomas, C. J.; Leister, W.; Maloney, D. J. Tetrahedron Lett. 2009, 50, 1710-1713. http://dx.doi.org/10.1016/j.tetlet.2009.01.120

21. Tosco, P.; Bertinaria, M.; Di Stilo, A.; Cena, C.; Sorba, G.; Fruttero, R.; Gasco, A. Bioorg. Med. Chem. 2005, 13, 4750-4759.

http://dx.doi.org/10.1016/j.bmc.2005.05.004

22. Kim, J. W.; Abdelaal, S. M.; Bauer, L. J. Heterocycl. Chem. 1995, 32, 611-620. http://dx.doi.org/10.1002/jhet.5570320241

23. Bellina, F.; Cauteruccio, S.; Di Fiore, A.; Rossi, R. Eur. J. Org. Chem. 2008, 5436-5445. http://dx.doi.org/10.1002/ejoc.200800738

24. Uehara, Y.; Mochizuki, M.; Matsuno, K.; Haino, T.; Asai, A. Biochem Biophys Res. Commun. 2009, 380, 627-631. 
25. Ferri, N.; Cazzaniga, S.; Mazzarella, L.; Curigliano, G.; Lucchini, G.; Zerla, D.; Gandolfi, R.; Facchetti, G.; Pellizzoni, M.; Rimoldi, I. Bioorg. Med. Chem. 2013, 21, 2379-2386.

http://dx.doi.org/10.1016/j.bmc.2013.01.063

26. Ferri, N.; Facchetti, G.; Pellegrino, S.; Pini, E.; Ricci, C.; Curigliano, G.; Rimoldi, I. Bioorg. Med. Chem. 2015, 23, 2538-2547.

27. Fan, L-C.; Teng, H-W.; Shiau, C-W.; Tai, W-T.; Hung, M-H.; Yang, S-H.; Jiang, J.-K.; Chen, K-F. Neoplasia 2015, 17, 687-696.

http://dx.doi.org/10.1016/j.neo.2015.08.007

28. Kuang, R.; Blythin, D.; Shih, N.-Y.; Shue, H.-J.; Chen, X.; Cao, J.; Gu, D.; Huang, Y.; Schwerdt, J. H.; Ting, P. C.; Wong, S.-C.; Xiao, L. PCT Int. Appl. 116 009, 2005. 